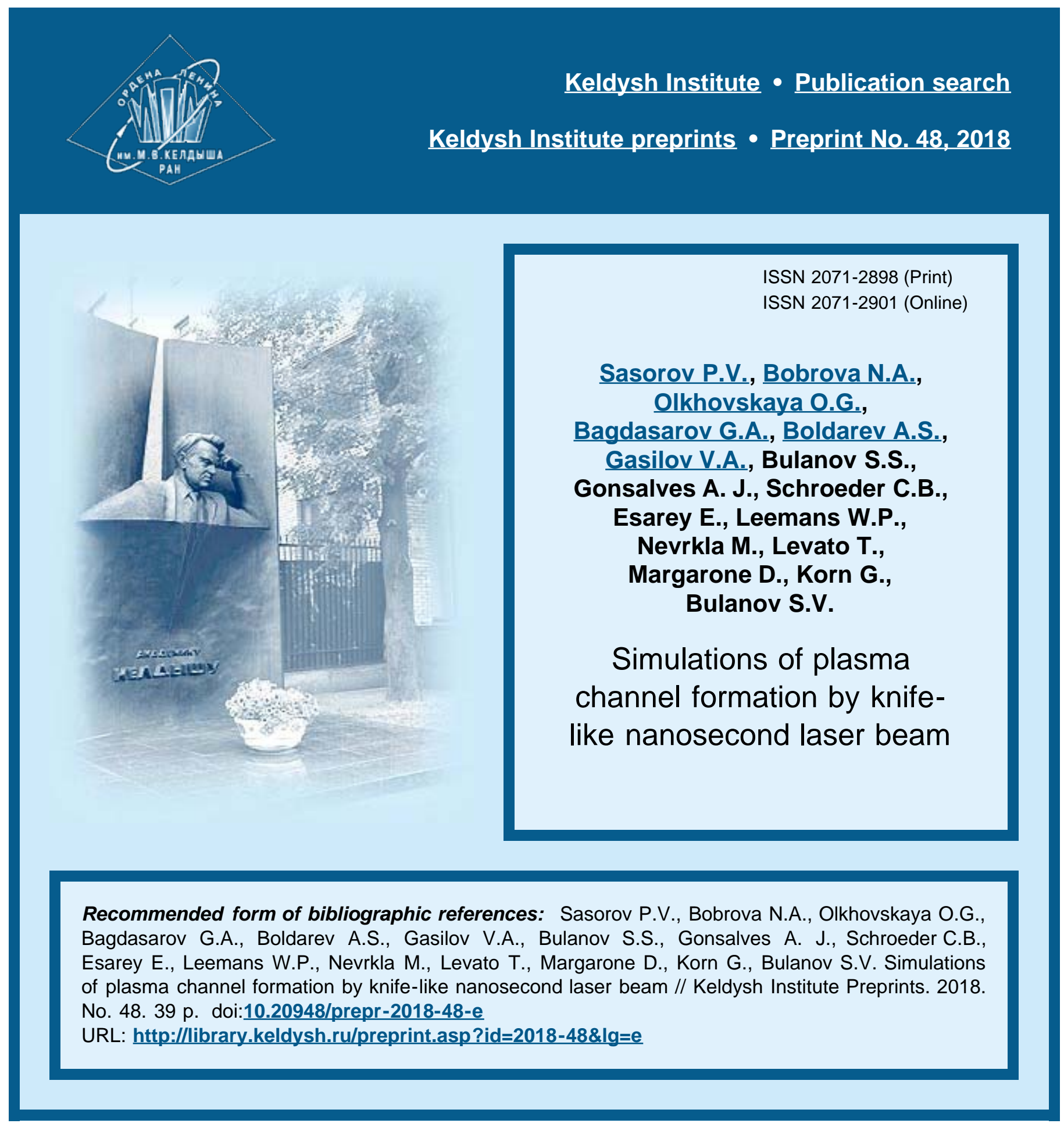


О р д ен а Л е н и н а

ИНСТИТУТ ПРИКЛАДНОЙ МАТЕМАТИКИ

имени М. В. Келдыша

Р осси йской академиинаук

P. V. Sasorov, N. A. Bobrova,

O. G. Olkhovskaya, G. A. Bagdasarov,

A. S. Boldarev, V. A. Gasilov, S. S. Bulanov,

A. J. Gonsalves, C. B. Schroeder, E. Esarey,

W. P. Leemans, M. Nevrkla, T. Levato,

D. Margarone, G. Korn, S. V. Bulanov

Simulations of plasma channel

formation by knife-like

nanosecond laser beam 
Sasorov P. V., Bobrova N. A., Olkhovskaya O. G., Bagdasarov G. A., Boldarev A. S., Gasilov V. A., Bulanov S. S. ${ }^{1}$, Gonsalves A. J. ${ }^{1}$, Schroeder C. B. ${ }^{1}$, Esarey E. ${ }^{1}$, Leemans W. P. ${ }^{1}$, Nevrkla M..$^{2}$, Levato $T .{ }^{2}$, Margarone $D .^{2}$, Korn $G .{ }^{2}$, Bulanov $S . V^{2,3,4}$

${ }^{1}$ Lawrence Berkeley National Laboratory, Berkeley, California 94720, USA ${ }^{2}$ ELI-Beamlines Project, 18221 Prague, Czech Republic

${ }^{3}$ National Institutes for Quantum and Radiological Science and Technology (QST), Kansai Photon Science Institute, 8-1-7 Umemidai, Kizugawa, Kyoto 619-0215, Japan

${ }^{4}$ A. M. Prokhorov General Physics Institute RAS, Moscow 119991, Russia

\section{Simulations of plasma channel formation by knife-like nanosecond laser beam}

The results of the simulations performed in KIAM are presented. Formation of channels in gas targets using a ns-laser is considered in relevant regimes: output energy - hundreds of Joules, nanosecond duration laser pulse, from 1 to 10 petawatt main laser pulse power. Such a kind of experiments are planned in the European laser center ELI-Beamline. They will develop a laser induced method of relativistic electrons acceleration, based on ideas investigated previously in NLBL. The magnetohydrodynamic codes NPINCH and MARPLE are used for 1D and 2D simulations of plasma channel formation in the region of elongated focus of knife-like nanosecond laser beam in under-critical gas density. Such plasma channel can be applied for transportation of high power femtosecond laser beams over large distances. The 2D simulations are performed to investigate the process of symmetrization of the channel, when the asymmetry of initial channel is caused by asymmetric deposition of the laser energy due to spatial structure of a plane focus of the laser beam. The simulations show how to reach the regimes of symmetric plasma channel formation. With 1D simulations the parameters of plasma channels for various cases under the condition of channel symmetrization are obtained.

Key words: plasma channel, nanosecond laser beam, 1D and 2D numerical simulation 
Сасоров П. В., Боброва Н. А., Ольховская О. Г., Багдасаров Г. А., Болдарев А. С., Гасилов В. А., Буланов С. С. ${ }^{1}$, Гонзалес A. ${ }^{1}$, Шрёдер K. ${ }^{1}$, Есари $\vartheta^{1} .^{1}$, Лиманс В. ${ }^{1}$, Невркла M. $^{2}$, Левато . $^{2}$, Маргароне Д. ${ }^{2}$, Корн.$^{2}$, Буланов С. В..$^{2,3,4}$

${ }^{1}$ Национальная Лаборатория им. Лоуренса в Беркли, Беркли, Калифорния, США

${ }^{2}$ Проект ЭЛИ-Источники, Прага, Чешская республика

${ }^{3}$ Национальный Институт Квантовой и Радиологической Науки и Технологии, Институт Фотонной науки Кансай, Киото, Япония

${ }^{4}$ Институт Общей Физики им. А. М. Прохорова РАН, Москва, РФ

\section{Моделирование образования плазменного канала ножевым наносекундным лазерным лучом}

Приводятся результаты выполненного в ИПМ им. М. В. Келдыша РАН моделирования формирования каналов в газовых мишенях с использованием наносекундного лазера в следующих режимах: вложенная энергия - сотни джоулей, лазерный импульс длительностью от 2 до 10 нс, мощность основного лазерного импульса от 1 до 10 ПВт. Такие эксперименты планируются в европейском лазерном центре ELI-Beamline. Они нацелены на развитие методов лазерного ускорения релятивиских электронов, исследованных ранее в NLBL. Магнитогидродинамические коды NPINCH и MARPLE используются для одномерного и двумерного моделирования образования плазменного канала в области вытянутого фокуса ножевого наносекундного лазерного луча при докритической плотности газа. Такой плазменный канал может быть применен для транспортировки высокомощных фемтосекундных лазерных лучей на большие расстояния. 2D-моделирование проводится для исследования процесса симметризации канала при асимметричном энерговкладе, обусловленом пространственной структурой плоского фокуса лазерного луча. Моделирование показывает, как достичь режимов формирования симметричного плазменного канала. При одномерном моделировании получены параметры плазменных каналов для различных случаев при условии симметризации каналов.

Ключевые слова: плазменный канал, наносекундный лазерный луч, одномерное и двумерное численное моделирование 


\section{Contents}

1 Deposition of laser beam energy $\begin{array}{ll}\text { in under-critical density plasma } & 6\end{array}$

1.1 Absorbtion . . . . . . . . . . . . . . . 6

1.2 Spatial distribution of knife-like laser beam intensity in paraxial focal spot . . . . . . . . . . . . . 6

$1.31 \mathrm{D}$ case . . . . . . . . . . . . . . . . . 8

1.4 1D case, axial irradiation by focused by an Axicon lens laser beam . . . . . . . . . . . . 8

2 Results of 2D $(x, y)$ simulations with MHD Code MARPLE $\quad 9$

2.1 Physical problem . . . . . . . . . . . . . . . . . . . 9

2.2 Numerical parameters . . . . . . . . . . . . . . . . . . 10

2.3 Results of the 2D simulations . . . . . . . . . . . . 12

2.3.1 The case of the focal angle $\alpha=0.0546 \ldots \ldots . . .212$

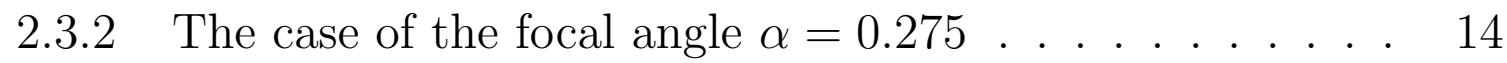

2.3.3 The case of the focal angle $\alpha=0.5 \ldots \ldots . . . . .14$

3 1D simulations with the MHD code NPINCH 19

3.1 General remarks . . . . . . . . . . . . . . . . . 19

3.2 Hydrogen gas target, laser pulse duration $\tau=2 \mathrm{~ns} \ldots \ldots . .20$

3.2.1 The same size of the focus as in 2D simulations . . . . 20

3.2.2 The same area of the focus as in 2D simulations . . . . 23

3.3 Hydrogen gas target, laser pulse duration $\tau=10 \mathrm{~ns} \ldots \ldots . .23$

3.3.1 The same focus area as in 2D simulations . . . . . . . 23

3.4 Argon gas target . . . . . . . . . . . . . . . 23

3.4.1 $\tau=2$ ns; the same same focus area as in 2D simulations 23

3.4.2 $\tau=10 \mathrm{~ns}$; the same focus area as in 2D simulations . . . 23

3.5 Plasma channel produced with the Axicon lens . . . . . . . . . . 29

$\begin{array}{llr}4 & \text { Conclusions } & 29\end{array}$

A Two-dimensional distribution of EM field in the cylindrical focus region $\quad 36$

A.1 2D s-polarised wave . . . . . . . . . . . . . . 36

A.2 Small angle of focusing . . . . . . . . . . . . 37 


\section{Introduction}

Method of relativistic electron beams acceleration, based on laser-wake-field acceleration, demonstrated very high performance [1]. It utilizes long propagation of high intensity laser beams along plasma wave guides, created during gas discharges in capillaries.

Plasma channels in neutral gas can be also produced in the region of an elongated focus of knife-like nanosecond duration laser beam [2]. This method is planned to be realized in ELI-Beamline. This paper is devoted to preliminary computer simulations of the physical processes playing important role during energy deposition of laser energy in such a geometry.

The laser beam is assumed to propagate perpendicularly to the long axis of the focus. The plasma channels can be used as waveguides for providing transportation of high power femtosecond laser beams. Below, we present the results of simulations of the plasma channel formation. Within the framework of the assumption that initial gas and the laser intensity along the axis perpendicular to the direction of the laser pulse propagation are homogeneous, the physical problem becomes two-dimensional. We use the MHD code MARPLE for the $2 \mathrm{D}$ simulations. The aim of the simulations is to study when plasma channel becomes cylindrically symmetric, since obviously symmetric channel are preferable for waveguiding. When an effective focal length is large substantially, the shape of the focus is elongated along the direction of the laser beam propagation. In this case, the symmetrization of the plasma channel may be questionable. Thus the first aim of the reported simulations is in finding the effective focal lengths required for channel production.

If symmetrization occures, the parameters of the plasma channel can be studied in details with the help of $1 \mathrm{D}$ code. We apply the $1 \mathrm{D}$ code NPINCH to perform multiparameteric studies of plasma channels.

In Sec. 1 we formulate the model of laser energy deposition in plasma for plasma density substantially lower than the critical density and for sufficiently small angles of radiation focusing. Then we implement this model in the code MARPLE. The model for 1D case was implemented in the code NPINCH (see Refs. [3, 4]) and tested by comparising with the results of experiment [3].

For the simulations of the plasma channel formation we use the updated version of the 2D code MARPLE (see Sec. 2). The 2D simulations show how to reach the regimes when the azimuthally symmetric plasma channel is formed. In Sec. 3 we present the results of 1D simulations using the code NPINCH, which provides the plasma channel parameters in a wide range of initial conditions (various durations of laser pulse, different gases, etc.). 


\section{Deposition of laser beam energy in under-critical density plasma}

\subsection{Absorbtion}

For known spatial distribution of laser intensity $c E^{2} / 8 \pi$ in the region of laser beam focus as a function of $(x, y, z, t)$, the inverse bremsstrahlung absorbtion in plasma is described by an imaginary part of permittivity: $\varepsilon=\varepsilon^{\prime}+i \varepsilon^{\prime \prime}$. We assume that the plasma density is under-critical, i.e. $n_{e} \ll n_{e c r}$. The rate of plasma heating due to the inverse bremsstrahlung process is given by expression:

$$
Q=\frac{|E|^{2}}{8 \pi} \omega \varepsilon^{\prime \prime}=\frac{|E|^{2}}{8 \pi} c \frac{2 \pi \varepsilon^{\prime \prime}}{\lambda}=F \frac{2 \pi \varepsilon^{\prime \prime}}{\lambda} .
$$

The function $F$ is proportional to $E^{2}$, i.e. $F=c|E|^{2} /(8 \pi), \varepsilon^{\prime \prime}$. The imaginary part of permittivity is $\varepsilon^{\prime \prime}$ is equal to

$$
\varepsilon^{\prime \prime}=\frac{4 \sqrt{2 \pi}}{3} \frac{z e^{4} n_{e}}{m_{e}^{1 / 2} T_{e}^{3 / 2}} \frac{\omega_{p e}^{2}}{\omega^{3}} \Lambda,
$$

where the Coulomb logarithm is

$$
\Lambda=\frac{1}{2} \ln \frac{2^{5} T_{e}^{3}}{\gamma^{5} \omega^{2} z^{2} e^{4} m_{e}} .
$$

It is assumed that $\frac{z e^{2}}{\hbar v_{T e}} \gg 1$ and $\frac{m v_{T e}^{3}}{z e^{2}} \gg \omega \gg \omega_{p e}$ (see Refs. [5, 6]).

The expressions (1)-(3) are used in Refs. [3, 4]. These expressions imply a fully ionized plasma. To take into account the case of partially ionized plasma they should be modified by changing $z^{3}$ with $z_{1} z^{2}$ in Eq. (2), and $z^{2}$ with $z_{1}^{2}$ in Eq. (3). Here $z_{1}=\max \{1, z\}$, and $z$ is equal to mean ion charge.

\subsection{Spatial distribution of knife-like laser beam intensity in paraxial focal spot}

If the laser beam focusing angle $\alpha$ of is much less than unity, and is larger that the ratio $n_{e} / n_{e c r}$, i.e. $1 \gg \alpha \gg n_{e} / n_{e c r}$, then refraction effects are negligibly small. Here $n_{e}$ is the electron density and $n_{e c r}=\sqrt{m_{e} \omega^{2} / 4 \pi e}$ is the critical plasma density. We neglect also depletion of the laser beam due to the inverse bremsstrahlung absorbtion in the focus. The laser beam propagation can be described in the frame of paraxial approximation for the Hemholtz equation. The Gaussian beams are well known solutions of this equation (see, for example, [7]). Generalizing these solutions for the case of knife-like electromagnetic 


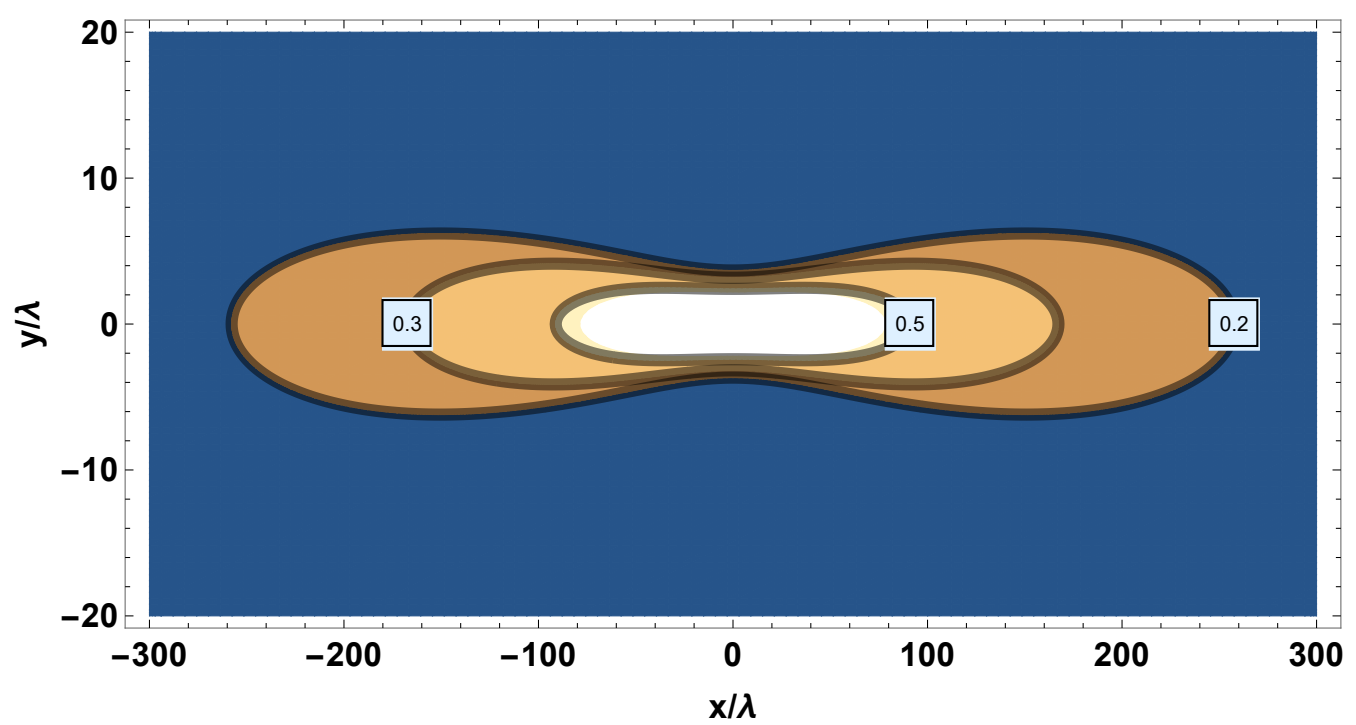

Fig. 1: The levels of $F$ in the focus region of the knife-like beam in the plane $(x / \lambda, y / \lambda)$ for $\alpha=0.055$ [see Eq. (4)]. The levels correspond to 0.5, 0.3 and 0.2 of the maximum value at $(x=0, y=0)$. The beam propagates in the $x$-direction.

beams, we obtain spatial distribution of the laser energy flux $F$. It is given by

$$
F=c \frac{|E|^{2}}{8 \pi}=J(t) \frac{2 \sqrt{\pi} \alpha}{\sqrt{4 \pi^{2} \alpha^{4} x^{2}+\lambda^{2}}} \exp \left(-\frac{4 \pi^{2} \alpha^{2} y^{2}}{4 \pi^{2} \alpha^{4} x^{2}+\lambda^{2}}\right) .
$$

Here $J(t)$ is a laser power per unit transverse length (along $z$-axis), $\lambda$ is the wavelength of the laser. Another way of derivation of Eq. (4) is presented in App. A. The laser beam propagates along the $x$-axis, whereas the laser beam intensity is assumed not to depend on the coordinate $z$. Peak value of $F$ is equal to

$$
F_{0}(t)=J(t) \frac{2 \sqrt{\pi} \alpha}{\lambda}
$$

The distribution (4) corresponds to the focusing angle (FWHM):

$$
\gamma=2 \arctan \alpha \sqrt{\ln 2},
$$

and to the transverse size $w$ (FWHM) of the focus:

$$
w=\frac{\sqrt{\ln 2}}{\pi \alpha} \lambda .
$$

Expressions (1)-(4) are implemented in the code MARPLE. Partial ionization of plasma is also taken into account.

Spatial distribution of laser energy flux $F$ in the plane $(x, y)$ corresponding to Eq. (4) is shown in Fig. 1. 


\section{$1.31 \mathrm{D}$ case}

We use the following expression for spatial distribution of laser energy flux $F$ :

$$
F\left(r<R_{\text {las }}, t\right)=F_{0}(t) \cos ^{2}\left(\frac{\pi r}{2 R_{\text {las }}}\right), \quad F\left(r>R_{\text {las }}, t\right)=0 \quad\left(r^{2}=x^{2}+y^{2}\right)
$$

in the cylindrically symmetric case. Here $F_{0}(t)=F_{\max }$ is the peak laser energy flux at the axis $(r=0)$ in terms of power per unit area of the beam cross section, $R_{\text {las }}$ is radius of the laser beam, so that its effective diameter (FWHM) is equal to $R_{\text {las }}$. The beam is assumed to propagate in $z$-direction.

The expressions (1)-(3) and (8), modified to take into account the effects of partial ionization of plasma, are implemented in the code NPINCH (see Refs. [3, 4]). Presented in Ref. [3] simulation results obtained with the code NPINCH and the results of experiments detecting soft X-ray radiation from Xe plasma, produced by heating of Xe gas jets by ns Nd-laser pulse, show a good agreement between the theory and experiment.

To have the same peak values of laser energy flux $F$ in the 1D and 2D cases we should set:

$$
F_{0}(t)=J(t) \frac{2 \sqrt{\pi} \alpha}{\lambda}
$$

\subsection{D case, axial irradiation by focused by an Axicon lens laser beam}

We may also simulate with 1D code azimuthally symmetric heating of a plasma by focusing of a laser beam by a conical Axicon lens (see Fig. 2).

To neglect inhomogeneity along the $z$-axis we assume that the Axicon lens of diameter $d$ produces a Bessel beam whose intensity is proportional to $J_{0}\left(k_{r} r\right)^{2}$, where $J_{0}$ is the zero-order Bessel function of the 1 st kind, and $k_{r}$ is the radial component of the wave vector. We approximate the spatial distribution of the laser energy flux $F$ as:

$$
F(r<d / 2, t)=F_{0}(t) \frac{a}{\sqrt{a^{2}+r^{2}}},
$$

where the parameter $a$, is equal to $a=1 / \pi k_{r}$. Then the length of the Axicon lens focus along the $z$-axis is

$$
\ell \simeq 2 \pi^{2} a d / \lambda
$$

and the power of the laser beam is approximately equal to

$$
P(t) \simeq \operatorname{\pi ad} F_{0}(t)
$$

in the limit $d \gg a$. 


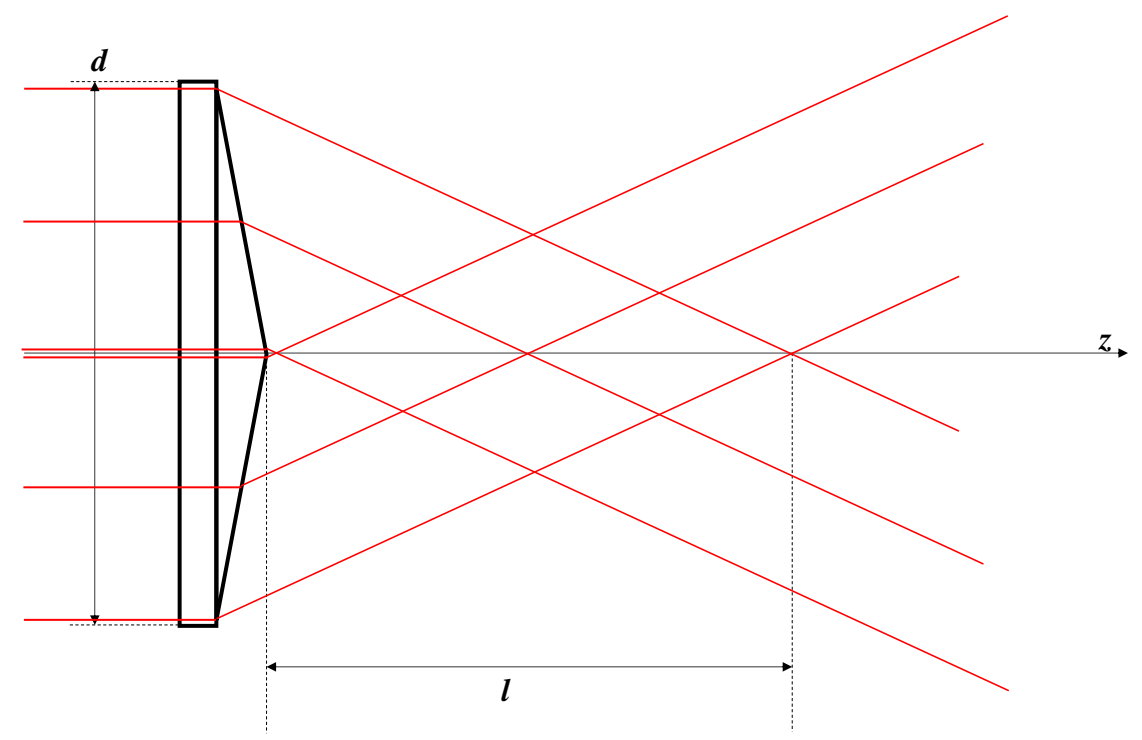

Fig. 2: Sketch of long focus formation with Axicon lens. The values of $\ell$ and $d$, and a relationship between them are defined in the text.

\section{Results of 2D $(x, y)$ simulations with MHD Code MARPLE}

\subsection{Physical problem}

Parameters of the reference simulation are the following:

- $J(0<t<2 \tau)=J_{t o t} \tau^{-1} \sin ^{2}(\pi t / 2 \tau) \quad J(t>2 \tau)=0$

- $J_{t o t}=12 \mathrm{~J} / \mathrm{cm}$

- $\tau=2 \mathrm{~ns}$

- $\lambda=1030 \mathrm{~nm}$

- $\alpha=0.0546$; corresponds to the focus spot size $w=5 \mu \mathrm{m}$ and the angle $\gamma \simeq 5.2^{\circ}$

- Hydrogen (Argon, Nitrogen)

- initial atomic density: $1.4 \times 10^{19} \mathrm{~cm}^{-3}$

- initial gas temperature $T=0.3 \mathrm{eV}$. 
- parameters of an initiating spark:

$-5 \mu \mathrm{m}$ diameter;

- initial ionization in the spark corresponds to the electron temperature of $T_{e}=1 \mathrm{eV}$;

- initial ion temperature $T_{i}=0.3 \mathrm{eV}$.

2D simulations with the code MARPLE are performed for Hydrogen only. Spatial distribution of the laser intensity in the $(x, y)$-plane for this case is shown in Fig. 1. The reference simulation parameters correspond approximately to the experiment [2], except replacing of the gases (Nitrogen and Argon) by Hydrogen.

To investigate the influence of the knife-like nanosecond laser beam structure on azimuthal (a)symmetry of the plasma channel we perform also two more simulations that differ from the reference one by the focal angle $\alpha$ and hence by the focal spot size. The set of parameters of the simulations is summarized in Tab. 1.

Table 1

\section{Parameters for the 2D simulations}

\begin{tabular}{ccccc}
\hline \hline$\alpha$ & $\gamma$ & $w$ & spark diameter & spark temperature \\
\hline 0.0546 & $5.2^{\circ}$ & $5 \mu \mathrm{m}$ & $5 \mu \mathrm{m}$ & $1 \mathrm{eV}$ \\
0.275 & $26^{\circ}$ & $1 \mu \mathrm{m}$ & $1 \mu \mathrm{m}$ & $2 \mathrm{eV}$ \\
0.5 & $45^{\circ}$ & $0.8 \mu \mathrm{m}$ & $1 \mu \mathrm{m}$ & $2 \mathrm{eV}$ \\
\hline \hline
\end{tabular}

Spatial distributions of fluxes $F$ in the focuses for $\alpha=0.275$ and for $\alpha=0.5$ are shown in Figs. 3 and 4, respectively. The contours of intensities in these figures correspond approximately to intensities at the contours in Fig. 1 for the case $\alpha=0.0546$. We intentionally increase initial temperature in the sparks for the 2 nd and 3rd simulation runs to provide the optical breakdown in the sparks of smaller sizes.

\subsection{Numerical parameters}

We summarize below the parameters of simulations and other numerical parameters for the 2D simulations considered in Sec. 2.1:

1. In the reference simulation for the focal angle $\alpha=0.0546$, the domain size is $2 \mathrm{~mm} \times 2 \mathrm{~mm}$. It corresponds to the domain in the $(x, y)$-plane: 


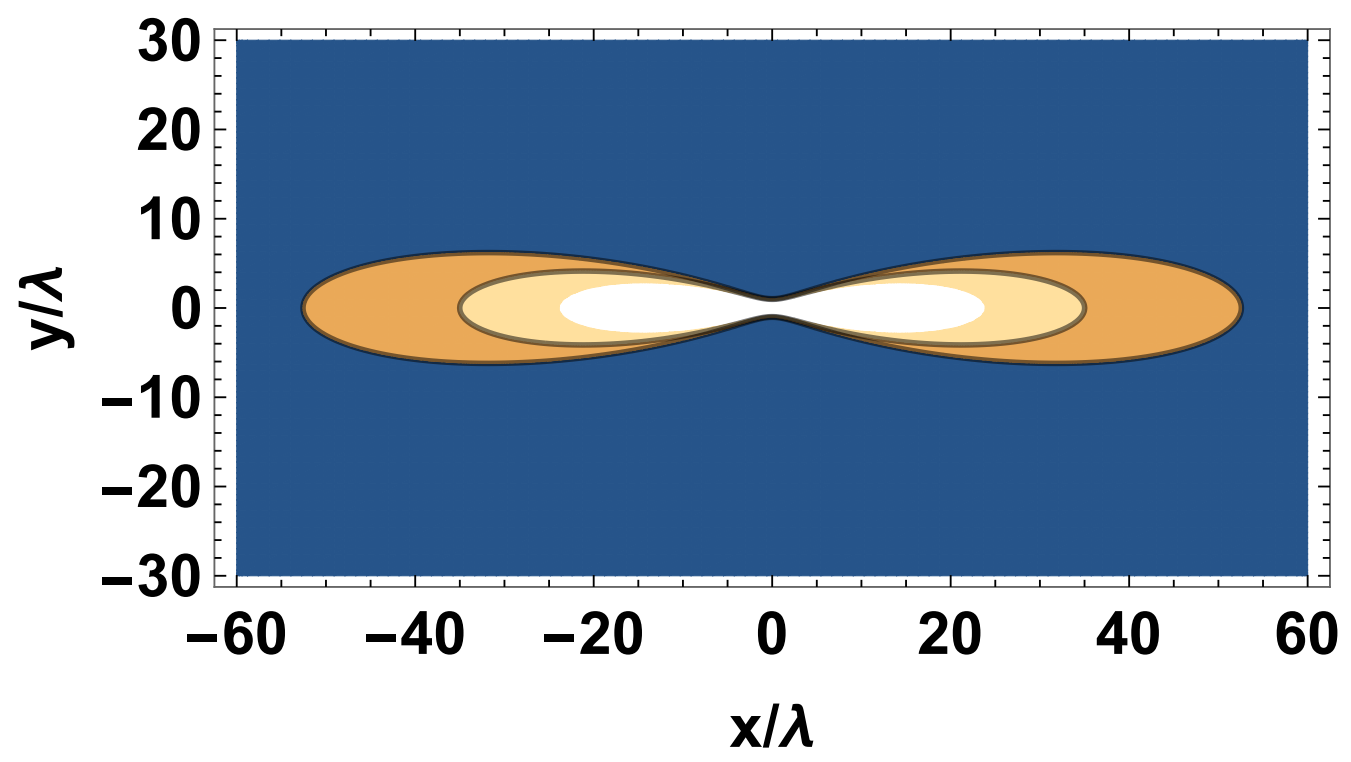

Fig. 3: The levels of laser energy flux $F$ in the focus region of the knife-like beam in the plane $(x / \lambda, y / \lambda)$ for $\alpha=0.275$ [see Eq. (4)]. The levels correspond to $0.1,0.06$ and 0.04 of the maximum value at $(x=0, y=0)$. Their absolute intensities for the same $J$ correspond to absolute intensities at the levels, shown in Fig. 1.

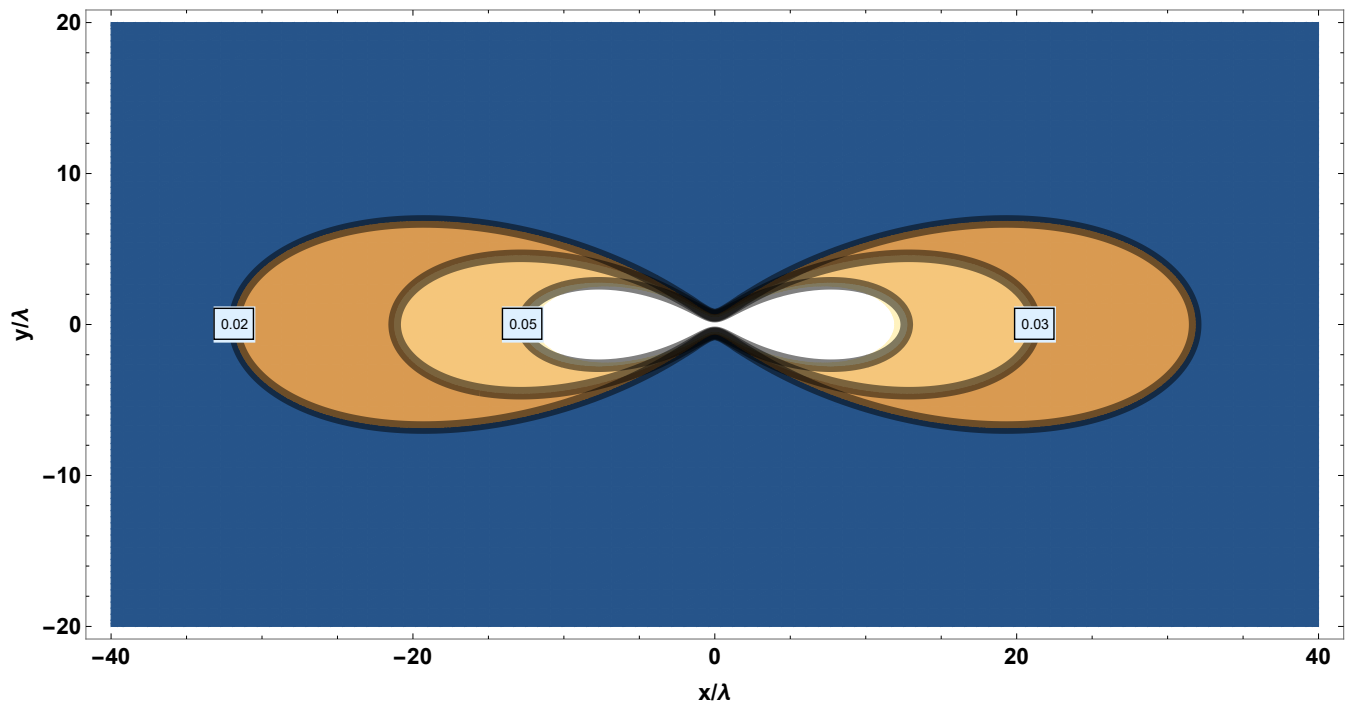

Fig. 4: The levels of laser energy flux $F$ in the focus region of the knife-like beam in the plane $(x / \lambda, y / \lambda)$ for $\alpha=0.5$ [see Eq. (4)]. The levels correspond to $0.05,0.03$ and 0.02 of the maximum value at $(x=0, y=0)$. Their absolute intensities for the same $J$ correspond approximately to absolute intensities of the levels, shown in Fig. 1. 
[-1 $\mathrm{mm} ;+1 \mathrm{~mm}] \times[-1 \mathrm{~mm} ;+1 \mathrm{~mm}]$. We use for discretization a twodimensional grid, composed by rectangular cells. The two-dimentional grid is the product of two one-dimensional grids. The smallest spatial step for both subgrids is equal to $0.25 \mu \mathrm{m}$ in the vicinity of the axis $(x=0, y=0)$, and the largest one is equal to $100 \mu \mathrm{m}$ in the vicinity of the outer boundary. Total size of the two-dimensional grid is $600 \times 600$. The simulation is performed for the time interval $t \in[0,10 \mathrm{~ns}]$.

2. In the second simulation for the focal angle $\alpha=0.287$, the domain size is $2 \mathrm{~mm} \times 2 \mathrm{~mm}$. It corresponds to the domain in the $(x, y)$-plane: $[-1 \mathrm{~mm} ;+1 \mathrm{~mm}] \times[-1 \mathrm{~mm} ;+1 \mathrm{~mm}]$. We use for discretization the twodimensional grid, composed by rectangular cells. The two-dimentional grid is a product of two one-dimensional grids. The smallest spatial step for both subgrids is equal to $0.05 \mu \mathrm{m}$ in the vicinity of the axis $(x=0, y=0)$, and the largest one is equal to $25 \mu \mathrm{m}$ in the vicinity of the outer boundary. Total size of the two-dimensional grid is $2700 \times 2700$. The simulation is performed for the time interval $t \in[0,15 \mathrm{~ns}]$.

3. In the third simulation for the focal angle $\alpha=0.5$, the domain size is $1 \mathrm{~mm} \times 1 \mathrm{~mm}$. It corresponds to the domain in the $(x, y)$-plane: $[0 ; 1 \mathrm{~mm}] \times[0 ; 1 \mathrm{~mm}]$, that is the quarter of the whole domain. We obtain solution in the whole domain $2 \mathrm{~mm} \times 2 \mathrm{~mm}$ by the axes $x$ and $y$ reflection. It is possible due to the reflectional symmetry of the physical problem under consideration. We use for discretization the two-dimensional grid, composed by rectangular cells. The two-dimentional grid is the product of two one-dimensional grids. The smallest spatial step for both subgrids is equal to $0.05 \mu \mathrm{m}$ in the vicinity of the axis $(x=0, y=0)$, and the largest one is equal to $25 \mu \mathrm{m}$ in the vicinity of the outer boundary. Total size of the two-dimensional grid is $1400 \times 1400$. The simulation is performed for the time interval $t \in[0,15 \mathrm{~ns}]$.

\subsection{Results of the $2 \mathrm{D}$ simulations}

\subsubsection{The case of the focal angle $\alpha=0.0546$}

Results of the reference simulation for the focal angle $\alpha=0.0546$ are shown in Figs. 5-6.

As seen the hot plasma bubble is asymmetric in this case. The simulation shows that about $0.64 \%$ of the total energy of the laser beam is absorbed in the focus. This result depends considerably on the dynamics of plasma in and around the focus during the laser pulse. 

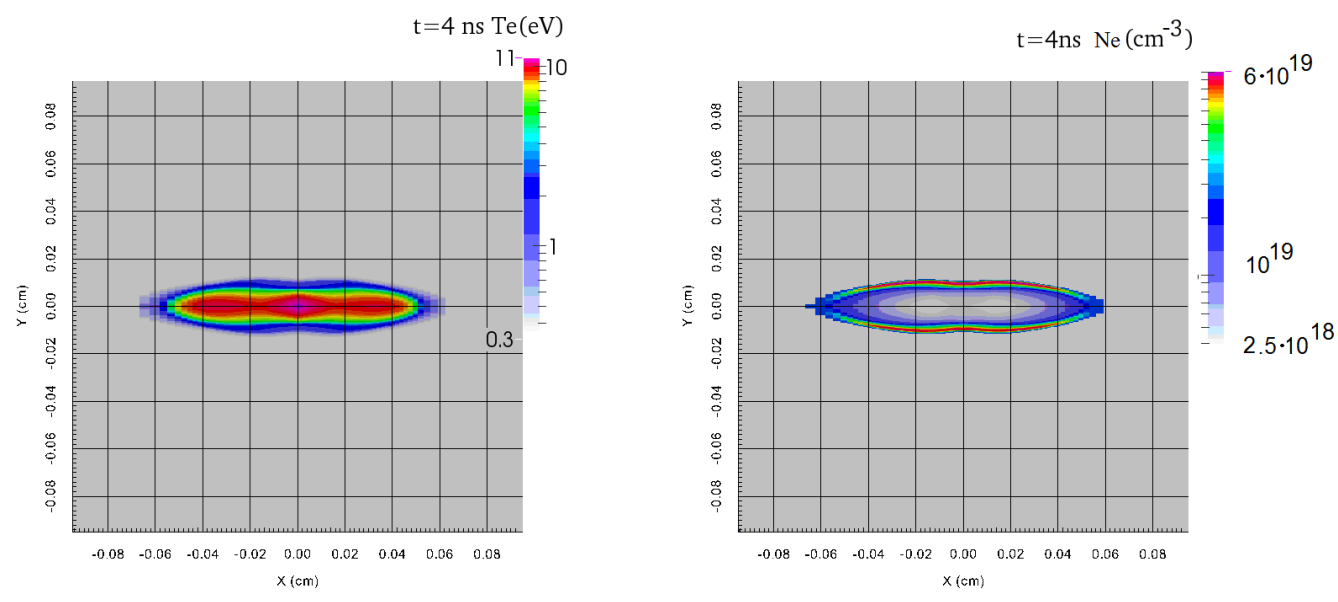

Fig. 5: Snapshots of spatial distributions of electron temperature $(\mathrm{eV})$ and density $\left(\mathrm{cm}^{-3}\right)$ at the time moment $t=4$ ns. $\alpha=0.0546$.
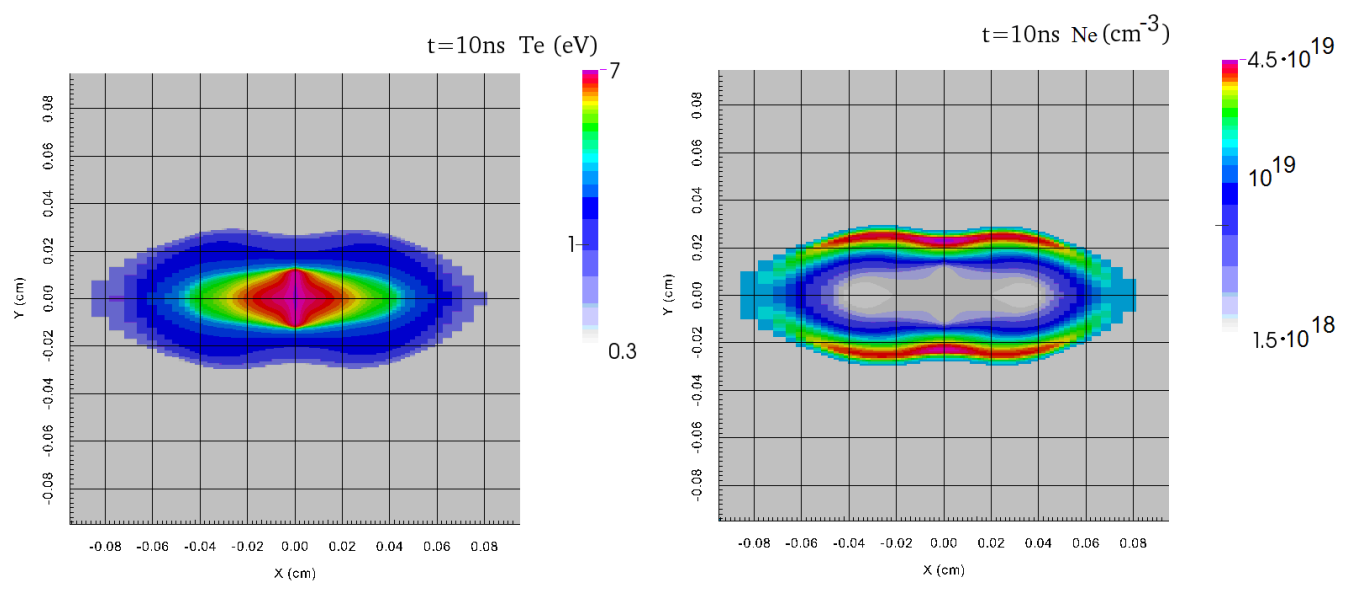

Fig. 6: Snapshots of spatial distributions of electron temperature $(\mathrm{eV})$ and density $\left(\mathrm{cm}^{-3}\right)$ at the moment of time $t=10$ ns. $\alpha=0.0546$. 

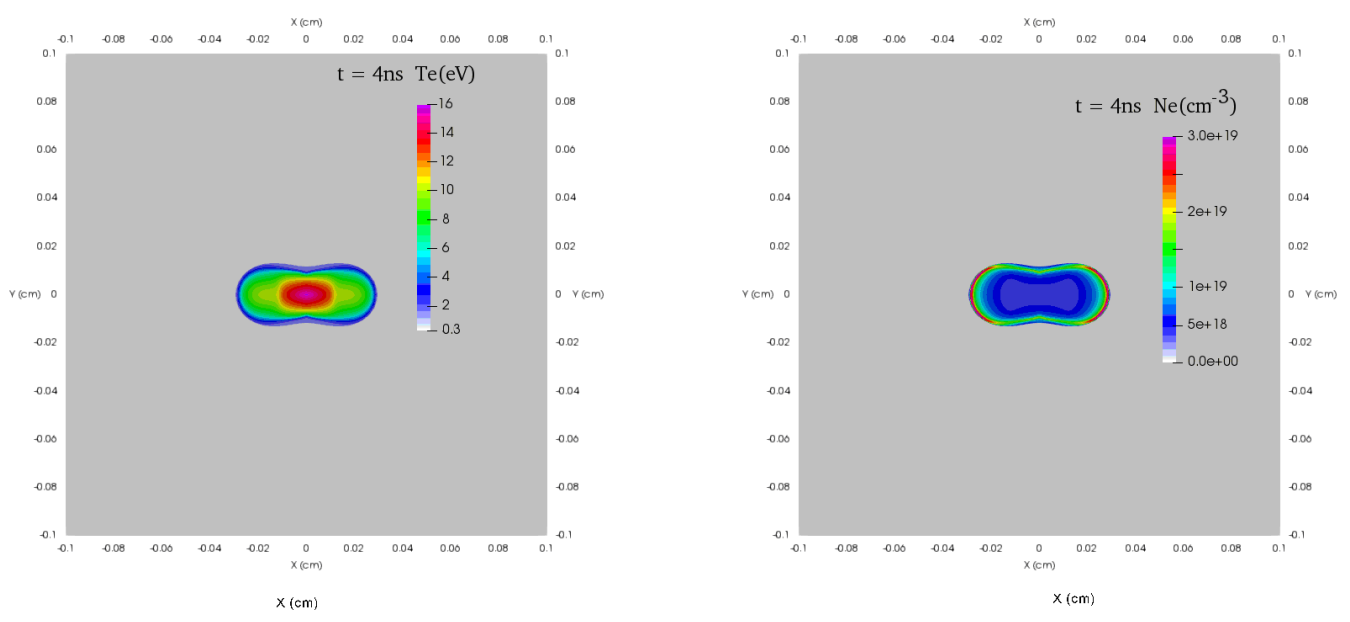

Fig. 7: Snapshots of spatial distributions of electron temperature (eV) and density $\left(\mathrm{cm}^{-3}\right)$ at the moment of time $t=4$ ns. $\alpha=0.275$.

\subsubsection{The case of the focal angle $\alpha=0.275$}

Results of the simulation for the focal angle $\alpha=0.275$ are shown in Figs. 711. In this case the hot plasma bubble becomes much more symmetric at the moments $t=10-15 \mathrm{~ns}$, than in the case of $\alpha=0.0546$. See especially Fig. 11 . The simulation shows that about $0.58 \%$ of the total energy of the laser beam is absorbed in the focus. This result depends considerably on the dynamics of plasma in and around the focus during the laser pulse.

\subsubsection{The case of the focal angle $\alpha=0.5$}

We show in this subsection the results of simulations of the plasma channel formation for large enough angle $\alpha$ of the knife-like ns laser beam: $\alpha=0.5$ and, hence, full angle at the half maximum of intensity $\gamma \simeq 45^{\circ}$. Fig. 4 shows laser beam intensity distribution for relevant magnitudes for this case in the plane $(x, y)$. Figs. 12 and 13 show the process of formation of hot almost completely ionized plasma bubble. We present color sequential snapshots of electron temperature and density distribution in the $(x, y)$-plane at the time moments $t=4$ and $15 \mathrm{~ns}$. We see that the distribution in the vicinity of the axis $x=y=0$ at late moments of time $t=10-15$ ns becomes much more symmetric than in the case of $\alpha=0.0546$. The distribution of electron temperature and electron and mass densities is shown in Figs. 14-16, respectively. Degree of (a)symmetry of the electron hollow at $t=15$ ns is shown in Fig. 17. Obtained plasma channel may be used for transportation of high power laser beams for a sufficiently long distances.

We note the shock wave formation, that propagates outside the hot bubble. Progressive pictures with the shock wave are shown in Figs. 12 and 13. The 


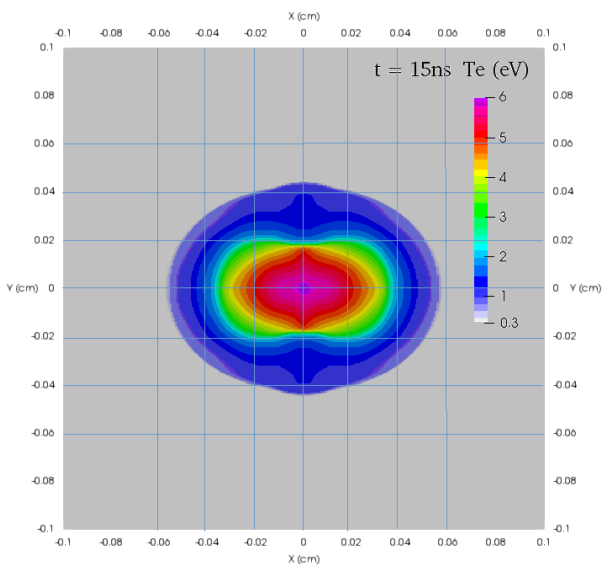

$x(\mathrm{~cm})$

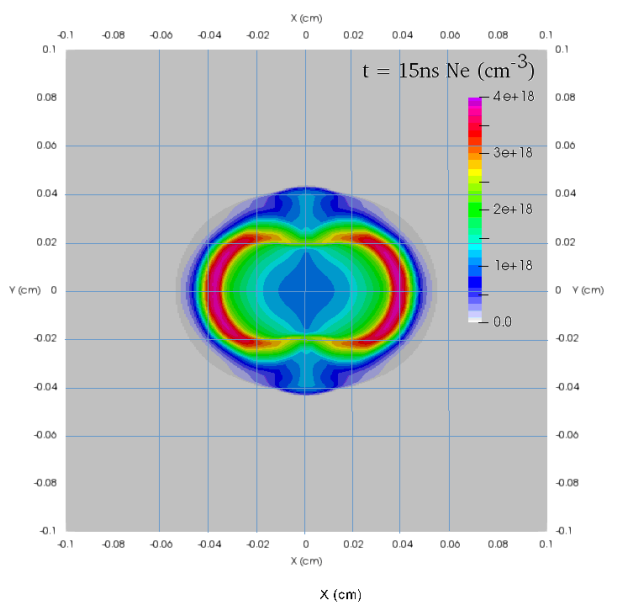

Fig. 8: Snapshots of spatial distributions of electron temperature $(\mathrm{eV})$ and density $\left(\mathrm{cm}^{-3}\right)$ at the moment of time $t=15 \mathrm{~ns}$. $\alpha=0.275$.
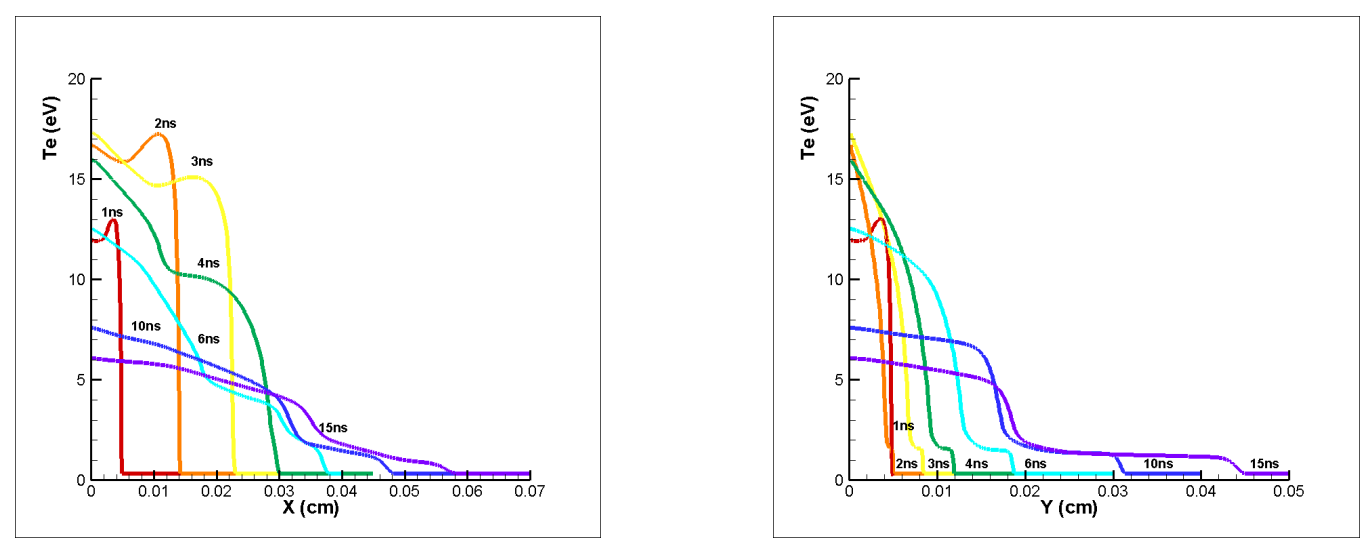

Fig. 9: Electron temperature distributions along the $\mathrm{x}$ - and $\mathrm{y}$-axes at different time moments. $\alpha=0.275$.
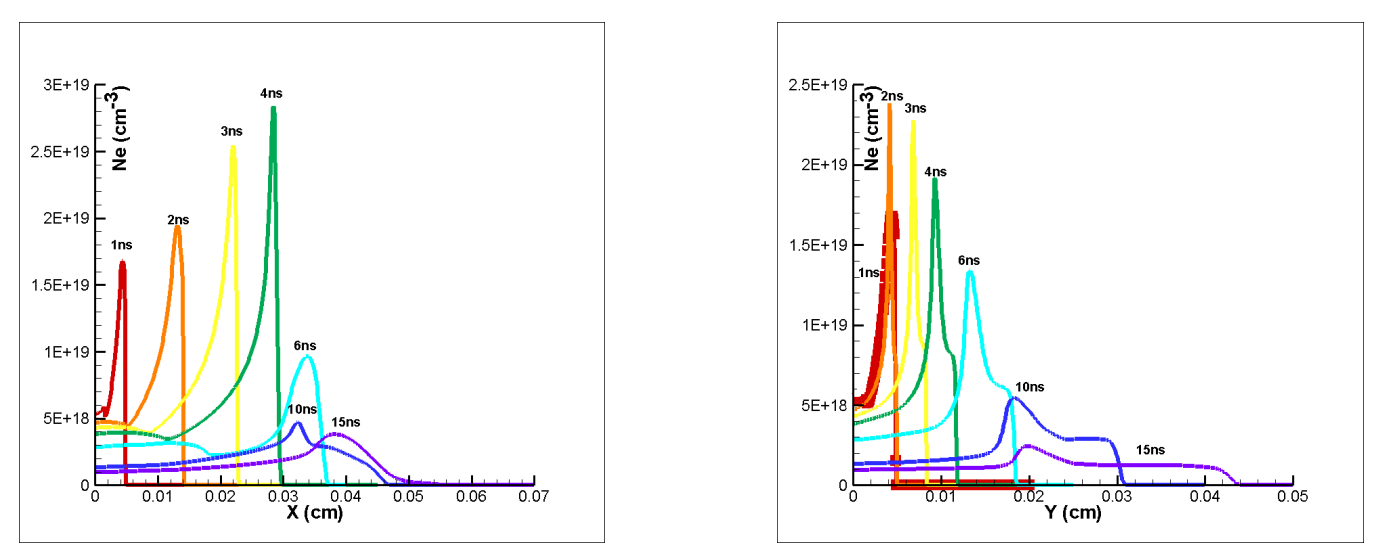

Fig. 10: Electron density distributions along the $\mathrm{x}$ - and $\mathrm{y}$-axes at different time moments. $\alpha=0.275$. 


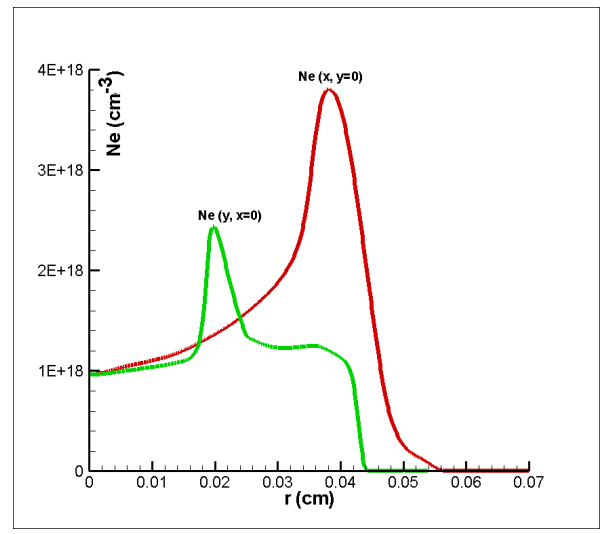

Fig. 11: Asymmetry of electron hollow at $t=15$ ns. $\alpha=0.275$.
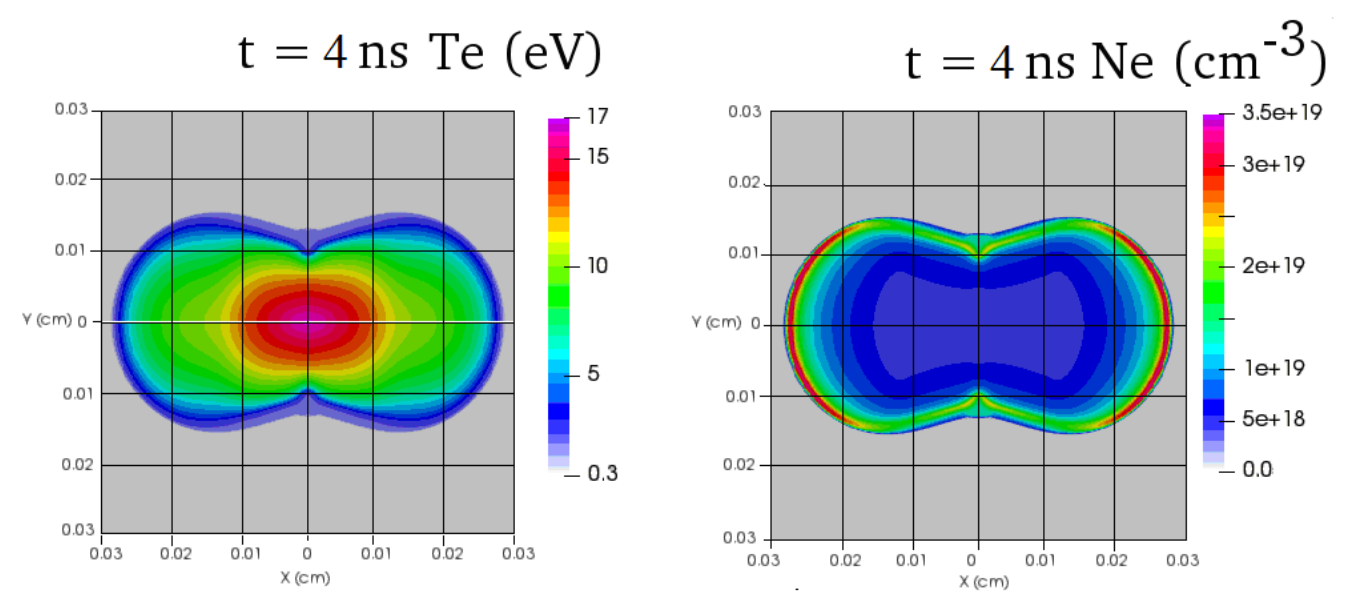

Fig. 12: Snapshots of spatial distributions of electron temperature $(\mathrm{eV})$ and density $\left(\mathrm{cm}^{-3}\right)$ at the time moment $t=4 \mathrm{~ns}$. Note the blowing up of the hot plasma bubble. $\alpha=0.5$. 

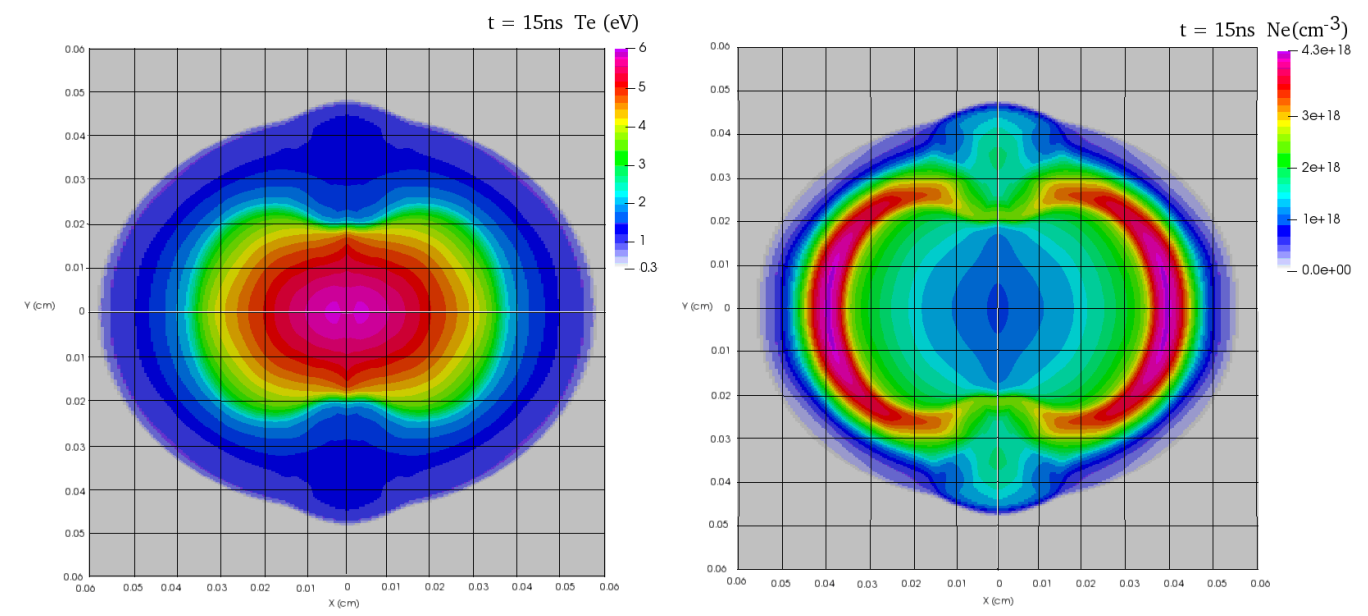

Fig. 13: Snapshots of spatial distributions of electron temperature $(\mathrm{eV})$ and density $\left(\mathrm{cm}^{-3}\right)$ at the moment of timet $=15 \mathrm{~ns}$. Note the blowing up of the hot plasma bubble. $\alpha=0.5$.

blust wave is manifested by distributions of mass density along the two rays in $\mathrm{x}$ and y-directions at different moments of times, as presented in Fig. 16. We may define a boundary of the hot ionized plasma bubble as a position of maximum of electron density along a radius. We see that the blust wave incircles the area, wider than the bubble on about $\sim 100-150 \mu \mathrm{m}$ in all the directions at $t=10 \mathrm{~ns}$, for example. Since this distance is not sufficiently large in comparison with the bubble size, the shock wave is closely attached to the hot bubble till the time $t=10 \mathrm{~ns}$. As the result, homogeneous gas in the front of the blust wave serves as a mitigating factor against growing asymmetry. For sufficiently longer periods, when the shock wave outruns considerably the growing bubble, the mitigating factor diminishes. At this stage the vortex motion exited due to asymmetry destroys completely the bubble due to turbulent mixing [8].

We see also that the electron temperature immediately behind the blust shock wave at $\sim 10 \mathrm{~ns}$ is of the order of $1.5 \mathrm{eV}$, and, as a result, degree of ionization is low enough. Hence the hot bubble expands after about the end of the laser pulse mainly due to thermal conductivity.

The simulation shows that about $0.72 \%$ of the total energy of the laser beam is absorbed in the focus. This number depends considerably also on plasma dynamics in and around the focus region during the laser pulse interaction with target. 

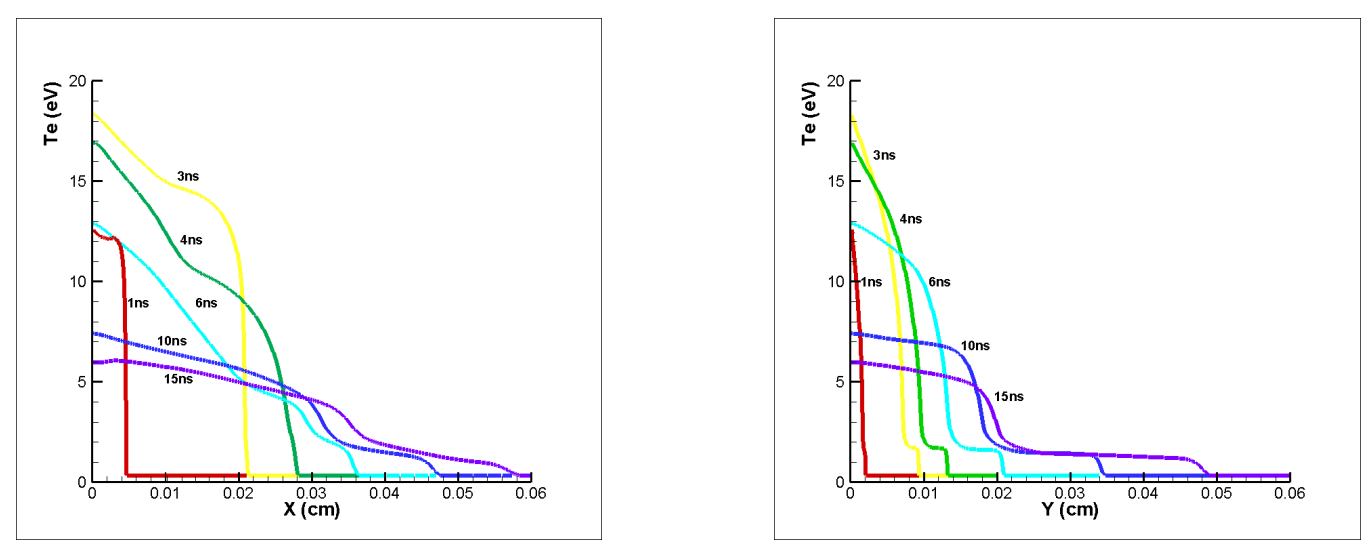

Fig. 14: Electron temperature distributions along the $x$ - and $y$-axes at different time moments. $\alpha=0.5$.
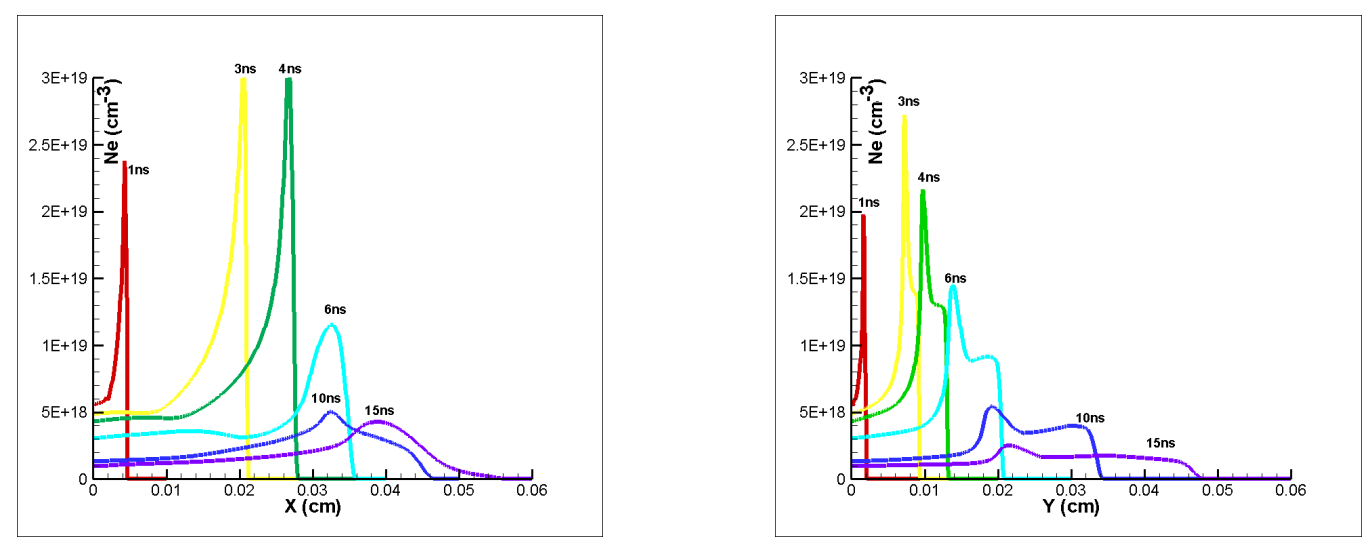

Fig. 15: Electron density distributions along the $x$ - and $y$-axes at different time moments. $\alpha=0.5$.
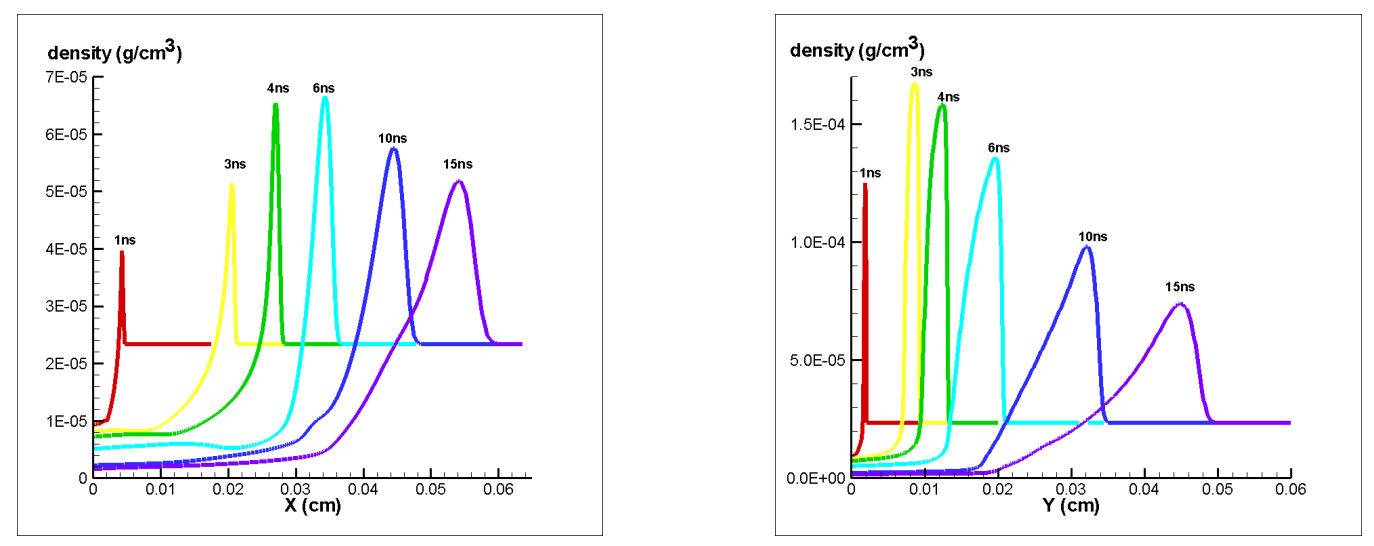

Fig. 16: Mass density distributions along the $x$ - and $y$-axes at different time moments. $\alpha=0.5$. 


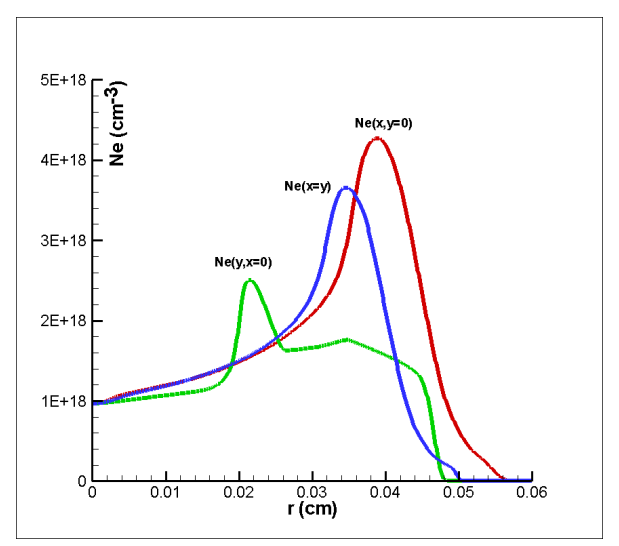

Fig. 17: Asymmetry of electron hollow at $t=15$ ns. $\alpha=0.5$.

\section{1D simulations with the MHD code NPINCH}

\subsection{General remarks}

Plasma channel, formed by absorbtion of the energy of knife-like beam in the focus region by a gas, can be useful for transportation of high power femtosecond laser pulse. The most suitable gas for production of such plasma channel is found to be Hydrogen (or Helium). Nevertheless, since experiments are often carried out with Argon and Nitrogen, we carried out the simulations for three types of gases: Hydrogen (our main option), Argon and Nitrogen.

The use of 1D code has apparent advantages for conducting simulations, aimed at multiparametric studies. However, ther is a question on how can we reproduce the geometry of $2 \mathrm{D}$ simulations in $1 \mathrm{D}$ simulations. According to presented 2D simulation results one can assume that at later stages of the evolution the plasma channel may be azimuthally symmetric. In this case, the plasma channel can be simulated in one-dimensional $(r, t)$-geometry. We should also take into account that physics of the laser absorbtion is governed mainly by power of laser energy and by a total flux passing a given point. The later means that we may choose for our 1D simulations the same peak power density in the beam focus and the same duration (and time profile) of the laser pulse. The remaining question concerns typical size of focus spot for $1 \mathrm{D}$ simulations. We have considered two cases. In the first one the sizes of focus spots are the same for $1 \mathrm{D}$ and for $2 \mathrm{D}$ simulations. In the second case the area, where intensity is higher than one half of maximum, is almost the same for the both geometries. This domain for our reference 2D simultation is shown in Fig. 1 by a white color.

As a result we have three sets of parameters:

- Gas: Hydrogen, Argon or Nitrogen; 
- $R_{\text {las }}=\lambda \pi^{-1} \alpha^{-1} \sqrt{\ln 2}(\rightarrow 5 \mu \mathrm{m}$; the same size $)$, or $\lambda \pi^{-1} \alpha^{-3 / 2}(3 \ln 2)^{1 / 4}$ $(\rightarrow 16 \mu \mathrm{m}$; approximately the same area);

- $\tau=2 \mathrm{~ns}$ or $10 \mathrm{~ns}$ (the present experiments).

We set $\alpha=0.0546$, as in the reference value in $2 \mathrm{D}$ simulations. There are 12 different combinations of laser and target parameters. We conducted simulations for all of them, but only the results of several of them are presented in this report.

We use the same time shape of the laser pulse as in the 2D case:

$$
F_{0}(t)=J(t) \frac{2 \sqrt{\pi} \alpha}{\lambda},
$$

where

$$
J(0<t<2 \tau)=\frac{J_{t o t}}{\tau} \sin ^{2} \frac{\pi \tau}{2 \tau}, \quad J(t>2 \tau)=0 .
$$

Axial irradiation with an Axicon lens: The formation of the plasma channel by use of axicon lens can be considered as alternative approach to achieve azimuthally symmetric plasma channel. We have performed simulation with the following parameters:

- $P(0<t<2 \tau)=\frac{\mathcal{E}}{\tau} \sin ^{2} \frac{\pi t}{2 \tau} \quad P(t>2 \tau)=0$, where $\mathcal{E}$ is total energy of laser pulse;

$\bullet \mathcal{E}=6 \mathrm{~J}$

- $\tau=2 \mathrm{~ns} ;$

- $d=2 \mathrm{~mm}$;

- $a=1 \mu \mathrm{m}$

- $\lambda=1.03 \mu \mathrm{m}$

- hydrogen;

- its initial density corresponds to atomic density of $1.4 \cdot 10^{19} \mathrm{~cm}^{-3}$.

These parameters correspond to $\ell \simeq 20 \mathrm{~mm}$. See expressions in Sec. 1.4 and Fig. 2.

\subsection{Hydrogen gas target, laser pulse duration $\tau=2 \mathrm{~ns}$}

\subsubsection{The same size of the focus as in $2 \mathrm{D}$ simulations}

The simulation results are presented in Figs. 18-21. 


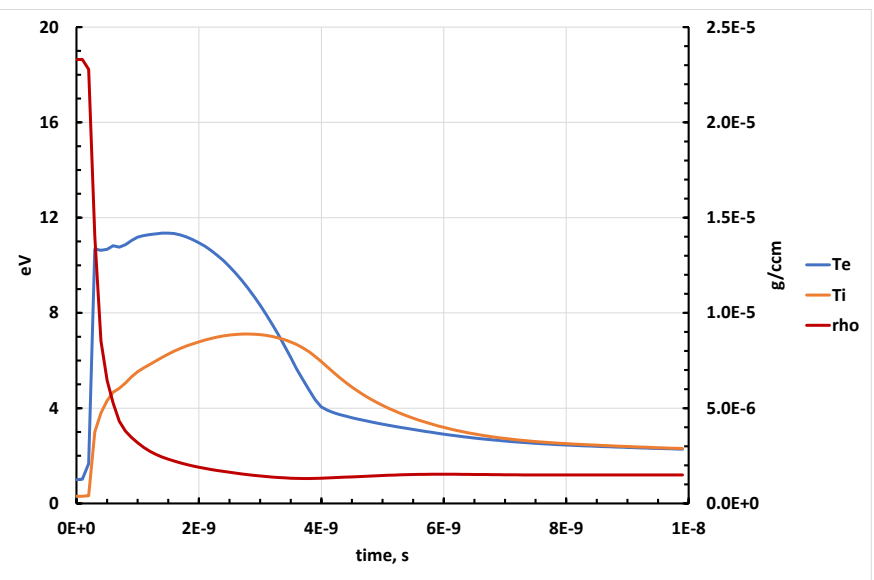

Fig. 18: Results of $1 \mathrm{D}$ simulation: Hydrogen, diameter of heated region $(\mathrm{FWHM})=5 \mu \mathrm{m}, \Delta t / 2=2 \mathrm{~ns}$ (FWHM). Temporal distributions of axial electron and ion temperatures and density.

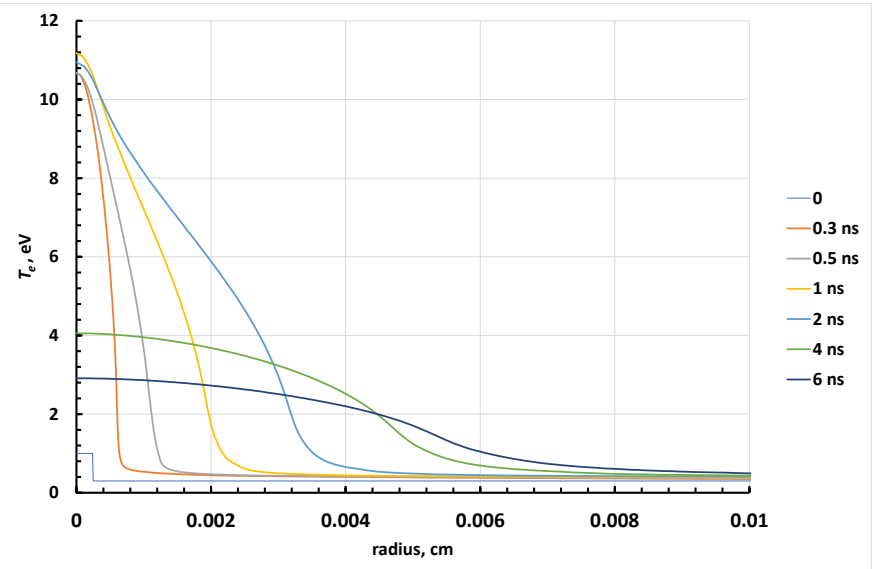

Fig. 19: Results of 1D simulation: Hydrogen, diameter of heated region $(\mathrm{FWHM})=5 \mu \mathrm{m}, \Delta t / 2=2 \mathrm{~ns}(\mathrm{FWHM})$. Radial profiles of $T_{e}$ at different moments of time. 


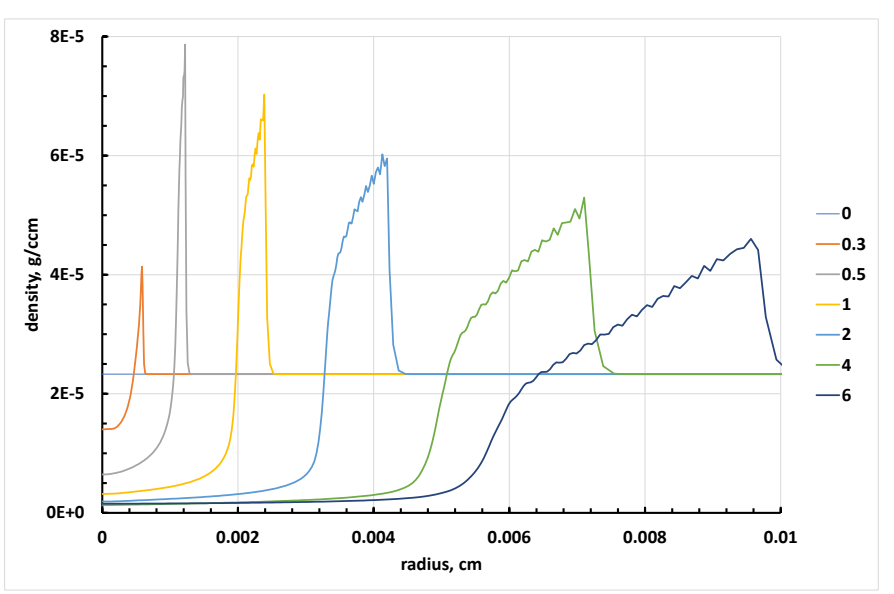

Fig. 20: Results of 1D simulation: Hydrogen, diameter of heated region $(\mathrm{FWHM})=5 \mu \mathrm{m}, \Delta t / 2=2 \mathrm{~ns}$ (FWHM). Radial profiles of mass density at different moments of time.

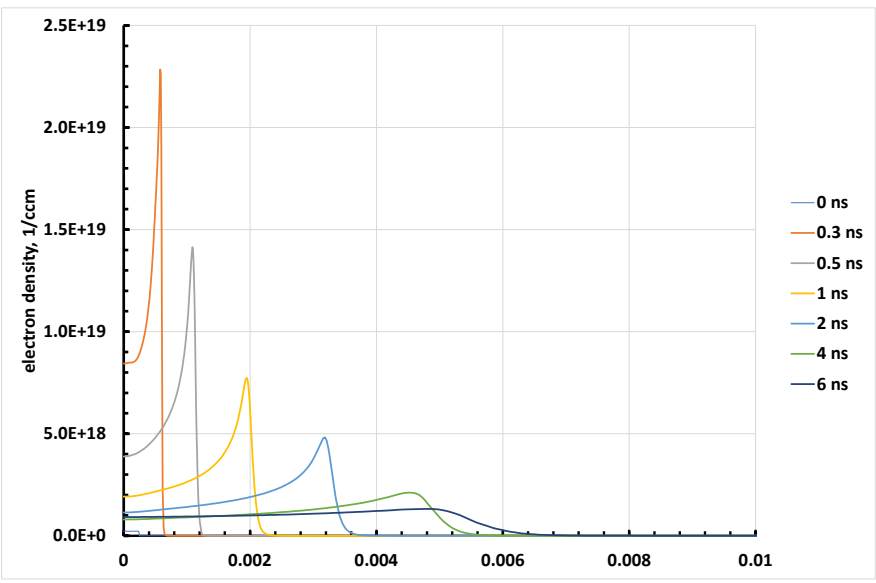

Fig. 21: Results of 1D simulation: Hydrogen, diameter of heated region $(\mathrm{FWHM})=5 \mu \mathrm{m}, \Delta t / 2=2 \mathrm{~ns}$ (FWHM). Radial profiles of $n_{e}$ at different moments of time. 


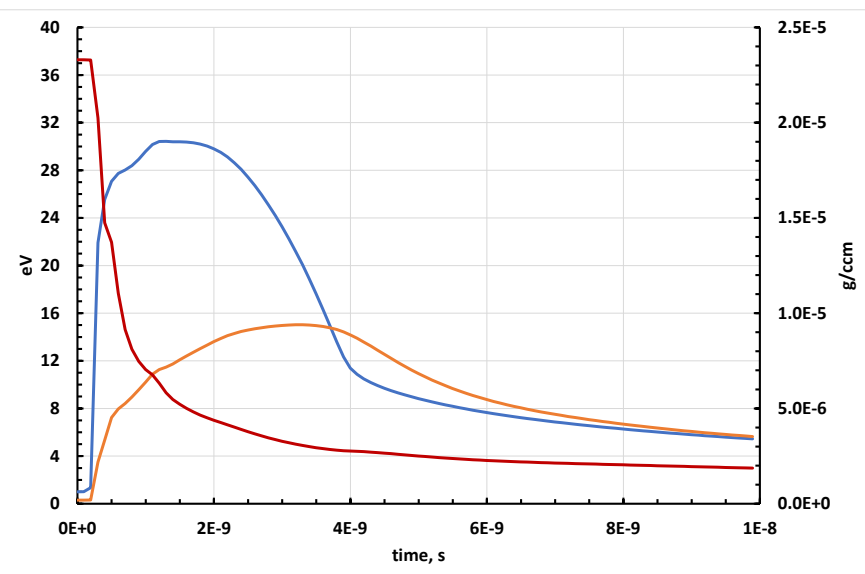

Fig. 22: Results of 1D simulation: Hydrogen, diameter of heating region $(\mathrm{FWHM})=20 \mu \mathrm{m}, \Delta t / 2=2 \mathrm{~ns}(\mathrm{FWHM})$. Time dependence of axial temperatures and density.

\subsubsection{The same area of the focus as in $2 \mathrm{D}$ simulations}

Results of the simulation in the case, when in $1 \mathrm{D}$ and $2 \mathrm{D}$ simulations the areas, where intensity is higher than one half of maximum, are the same, are shown in Figs. 22-25.

\subsection{Hydrogen gas target, laser pulse duration $\tau=10 \mathrm{~ns}$}

\subsubsection{The same focus area as in $2 \mathrm{D}$ simulations}

Results of the simulation are shown in Figs. 26-29.

\subsection{Argon gas target}

\subsection{1 $\tau=2 \mathrm{~ns}$; the same same focus area as in $2 \mathrm{D}$ simulations}

We decreased the initial density of Argon compared to the simulations in Secs. 3.2 and 3.3 to keep similar electron density in the plasma channel. Initial density of Ar is equal to $0.15 \mathrm{mg} / \mathrm{cm}^{-3}$. Results of the simulation are shown in Figs. 30-33.

\subsection{2 $\tau=10 \mathrm{~ns}$; the same focus area as in $2 \mathrm{D}$ simulations}

We decreased the initial density of Argon compare to the simulations in Secs. 3.2 and 3.3 to keep similar electron density in the plasma channel. Initial density of 


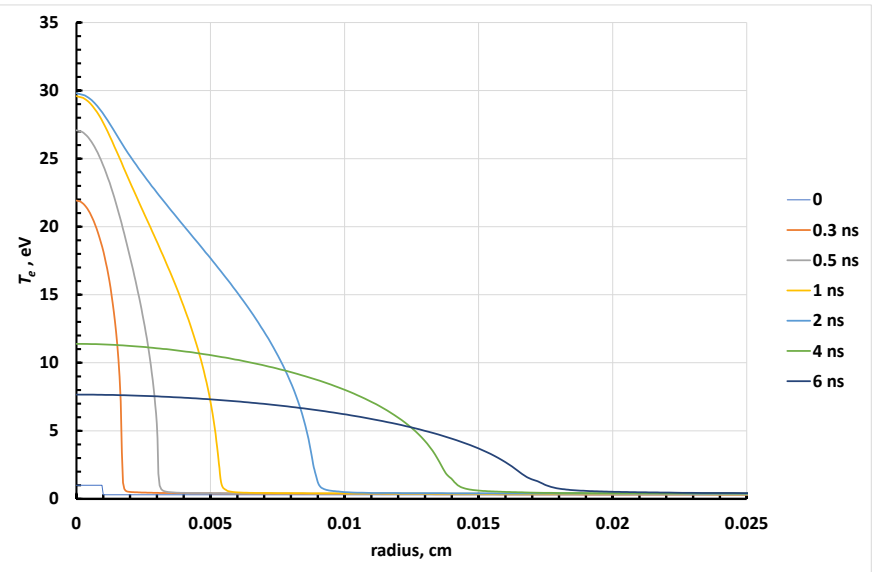

Fig. 23: Results of 1D simulation: Hydrogen, diameter of heating region $(\mathrm{FWHM})=20 \mu \mathrm{m}, \Delta t / 2=2 \mathrm{~ns}(\mathrm{FWHM})$. Radial profile of $T_{e}$ at different moments of time.

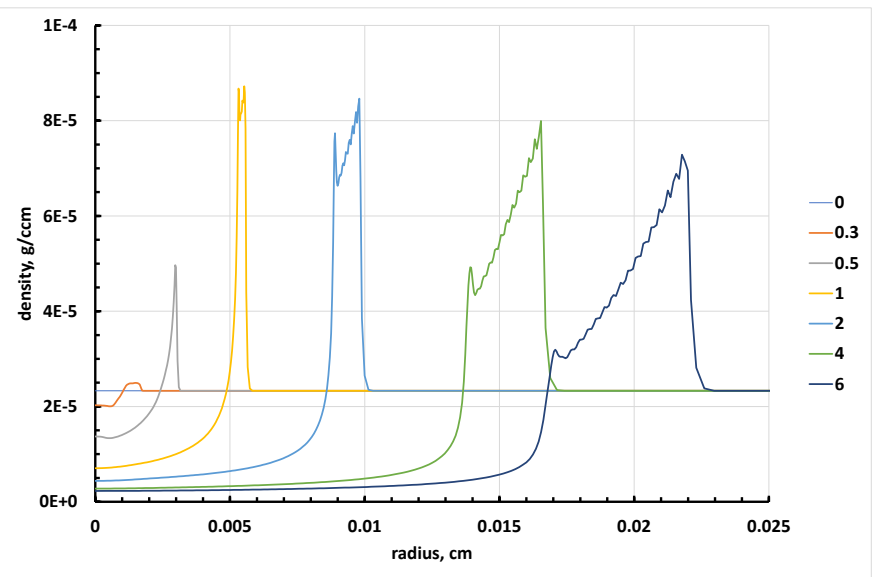

Fig. 24: Results of 1D simulation: Hydrogen, diameter of heating region $(\mathrm{FWHM})=20 \mu \mathrm{m}, \Delta t / 2=2 \mathrm{~ns}$ (FWHM). Radial profile of mass density at different moments of time. 


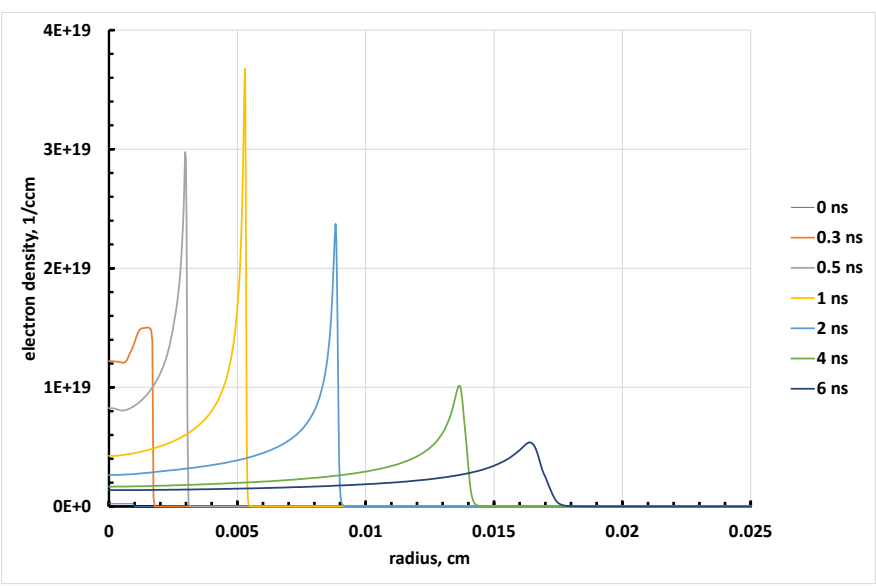

Fig. 25: Results of 1D simulation: Hydrogen, diameter of heating region $(\mathrm{FWHM})=20 \mu \mathrm{m}, \Delta t / 2=2 \mathrm{~ns}(\mathrm{FWHM})$. Radial profile of $N_{e}$ at different moments of time.

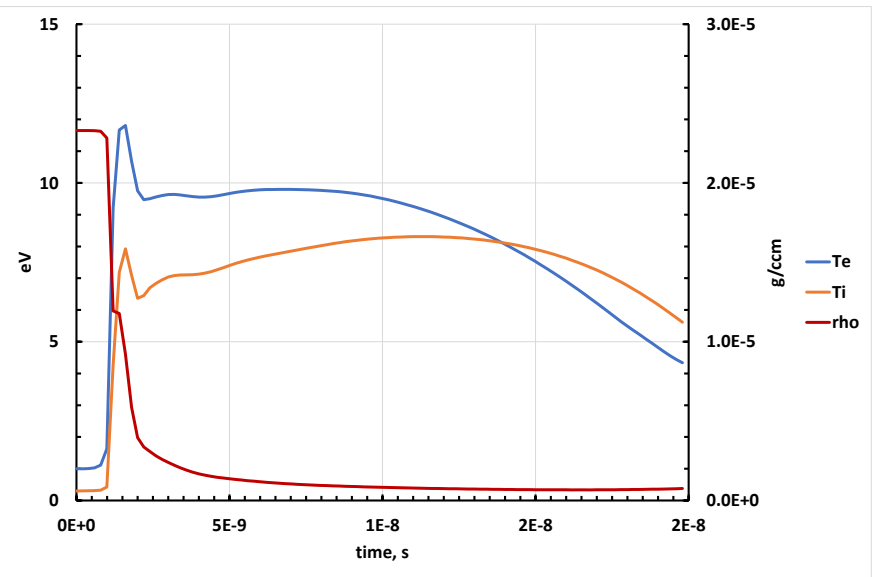

Fig. 26: Results of 1D simulation: Hydrogen, diameter of heating region $(\mathrm{FWHM})=20 \mu \mathrm{m}, \Delta t / 2=10 \mathrm{~ns}(\mathrm{FWHM})$. Temporal dependencies of axial temperatures and density. 


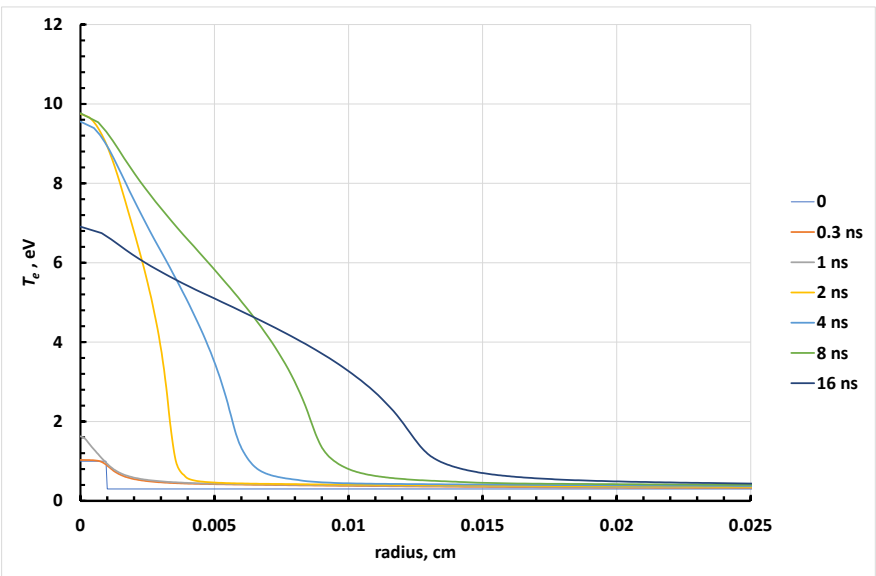

Fig. 27: Results of 1D simulation: Hydrogen, diameter of heating region $(\mathrm{FWHM})=20 \mu \mathrm{m}, \Delta t / 2=10 \mathrm{~ns}(\mathrm{FWHM})$. Radial profiles of $T_{e}$ at different moments of time.

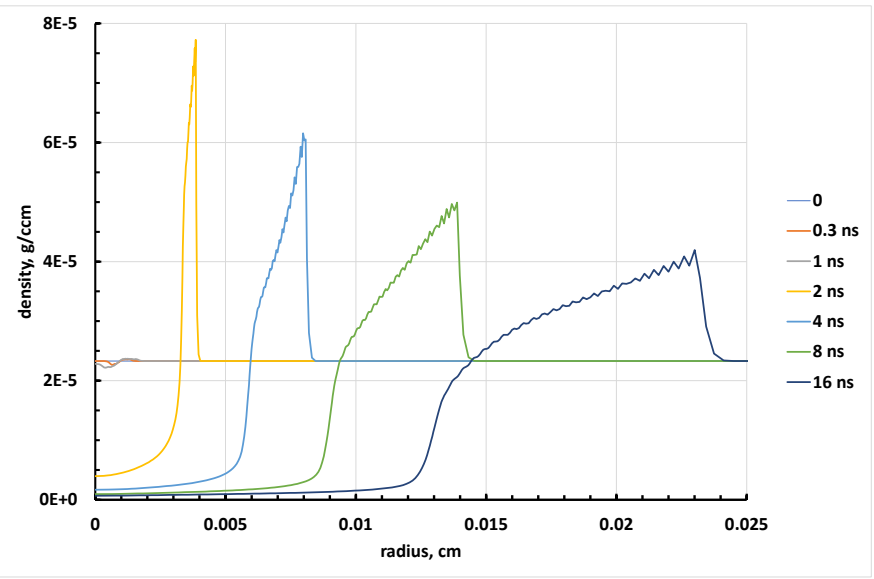

Fig. 28: Results of 1D simulation: Hydrogen, diameter of heating region $(\mathrm{FWHM})=20 \mu \mathrm{m}, \Delta t / 2=10 \mathrm{~ns}$ (FWHM). Radial profiles of mass density at different moments of time. 


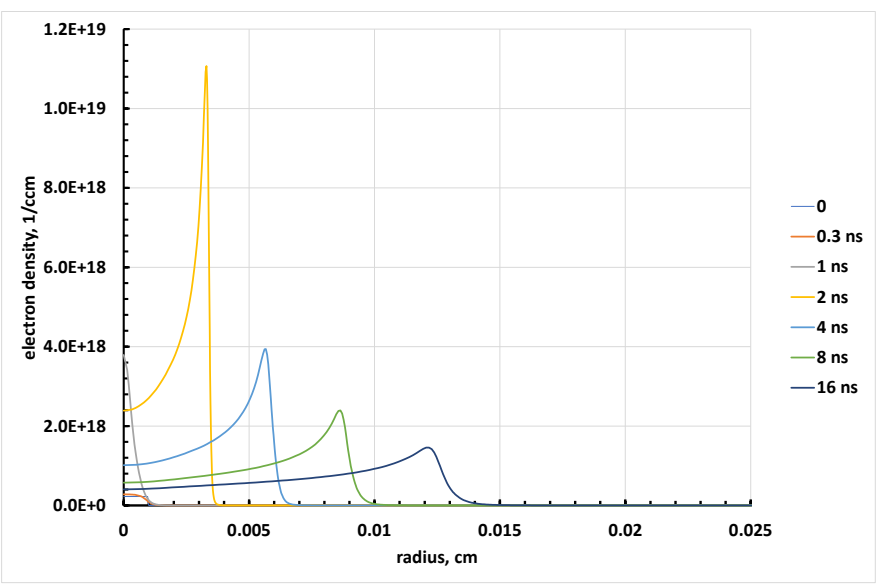

Fig. 29: Results of 1D simulation: Hydrogen, diameter of heating region $(\mathrm{FWHM})=20 \mu \mathrm{m}, \Delta t / 2=10 \mathrm{~ns}(\mathrm{FWHM})$. Radial profiles of $n_{e}$ at different moments of time.

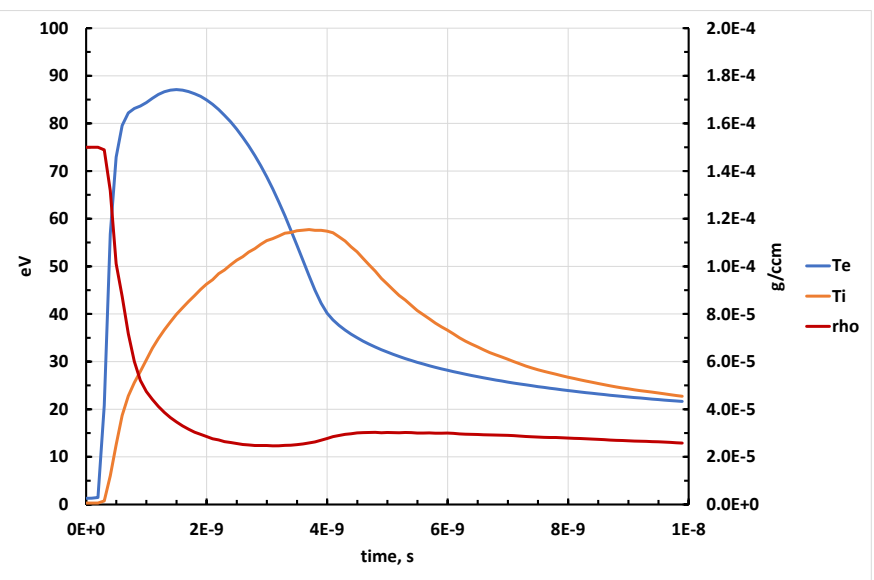

Fig. 30: Results of 1D simulation( Argon, diameter of heating region (FWHM) $=20 \mu \mathrm{m}, \Delta t / 2=2 \mathrm{~ns}$ ). Temporal dependences of axial temperatures and density. 


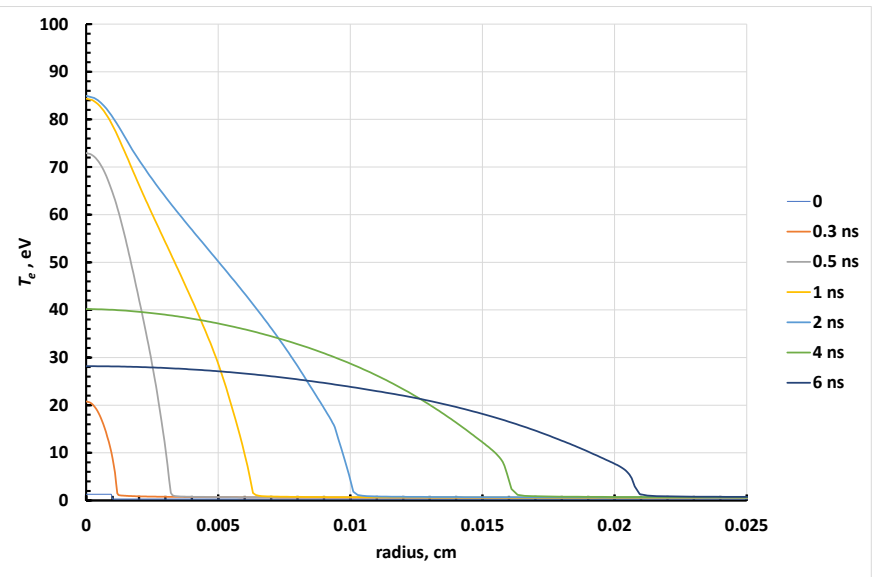

Fig. 31: Results of 1D simulation (Argon, diameter of heating region (FWHM) $=20 \mu \mathrm{m}, \Delta t / 2=2 \mathrm{~ns})$. Radial profiles of $T_{e}$ at different moments of time.

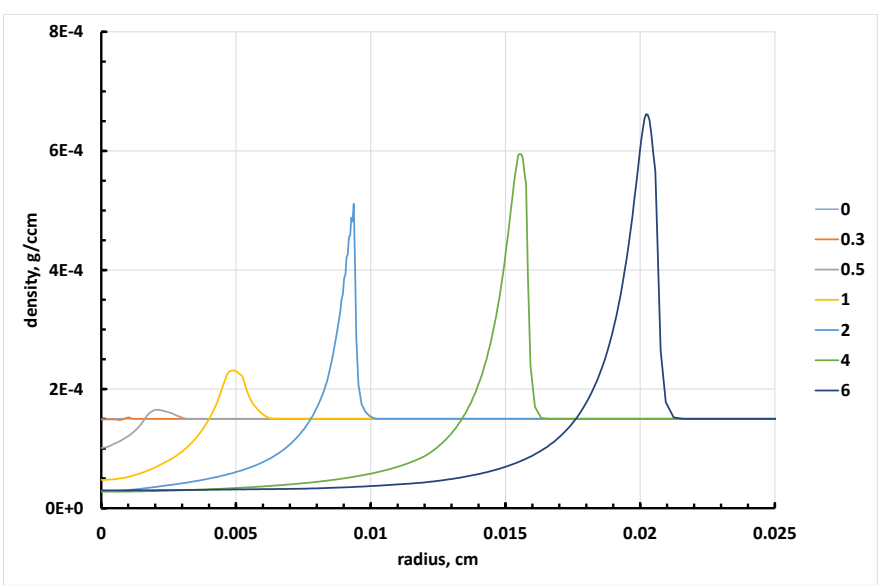

Fig. 32: Results of 1D simulation (Argon, diameter of heating region (FWHM) $=20 \mu \mathrm{m}, \Delta t / 2=2 \mathrm{~ns}$ ). Radial profiles of mass density at different moments of time. 


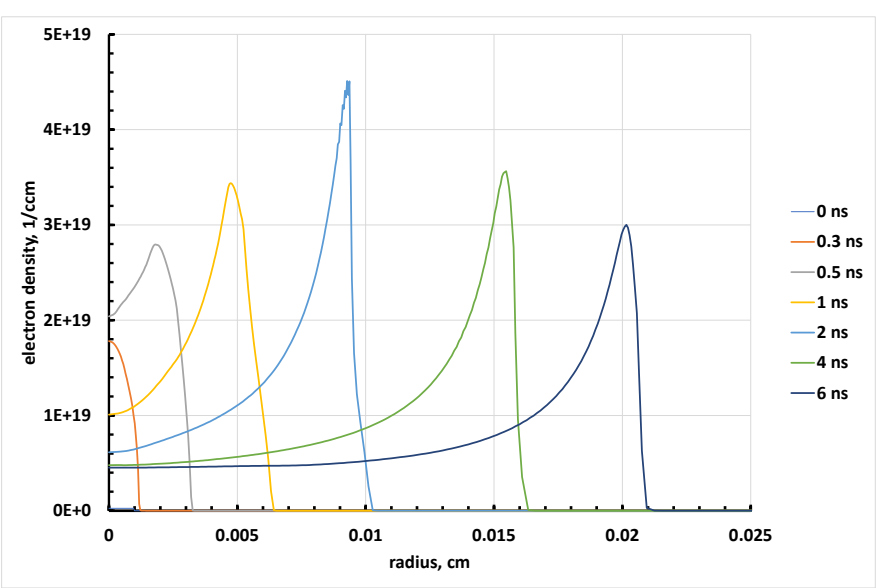

Fig. 33: Results of 1D simulation (Argon, diameter of heating region (FWHM) $=20 \mu \mathrm{m}, \Delta t / 2=2 \mathrm{~ns})$. Radial profiles of $N_{e}$ at different moments of time.

Ar is equal to $0.15 \mathrm{mg} / \mathrm{cm}^{-3}$. Results of the simulation are shown in Figs. 34-37.

\subsection{Plasma channel produced with the Axicon lens}

Results of the simulation are shown in Figs. 38-41.

\section{Conclusions}

The model used to describe energy deposition in the focus of the laser beam is tested by comparing its predictions with the results of experiment [3]. The model is implemented in the code NPINCH. We test the code MARPLE by simulating the same 1D problem with both codes in 1D and 2D regimes, respectively, and obtain that the both codes give the same results with a reasonable accuracy.

The reference 2D simulation with the code MARPLE, corresponding to $\gamma=$ $5.2^{\circ}(\alpha=0.0546)$, shows that the plasma channel, formed in this case, is highly asymmetric. To find a way towards azimuthally symmetric channel formation in experiments we perform two 2D simulations with $\gamma=26^{\circ}(\alpha=0.275)$ and $\gamma=45^{\circ}(\alpha=0.5)$. The simulations show that approximately azimuthally symmetric plasma channels in the close vicinity of its axis are formed after about $10 \mathrm{~ns}$ after peak of laser pulse power is reached. We can conclude, that optimizing the laser-target parameters (duration of laser pulse, its energy, time delay and angle of focusing of the laser beam $\gamma$ ), it is possible to find an optimal 


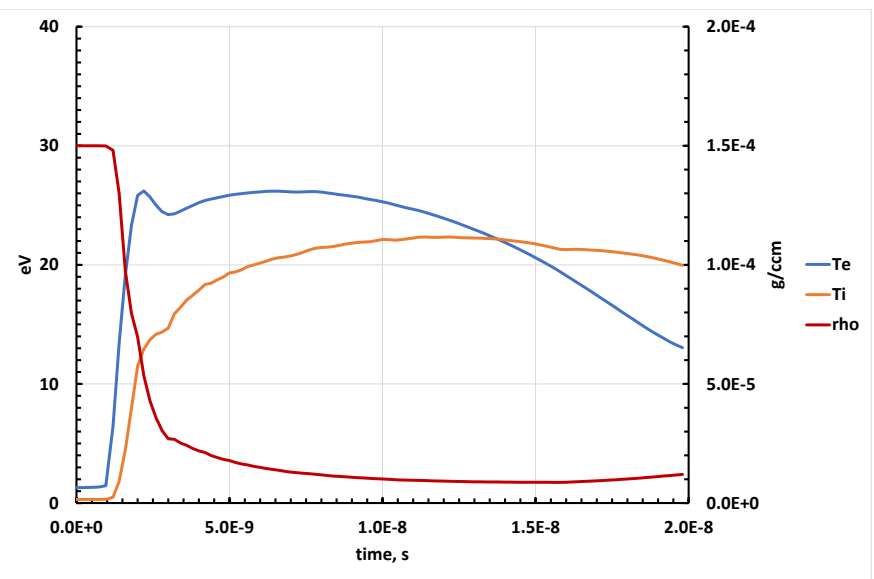

Fig. 34: Results of 1D simulation (Argon, diameter of heating region (FWHM) $=20 \mu \mathrm{m}, \Delta t / 2=2 \mathrm{~ns})$. Temporal dependencies of axial temperatures and density.

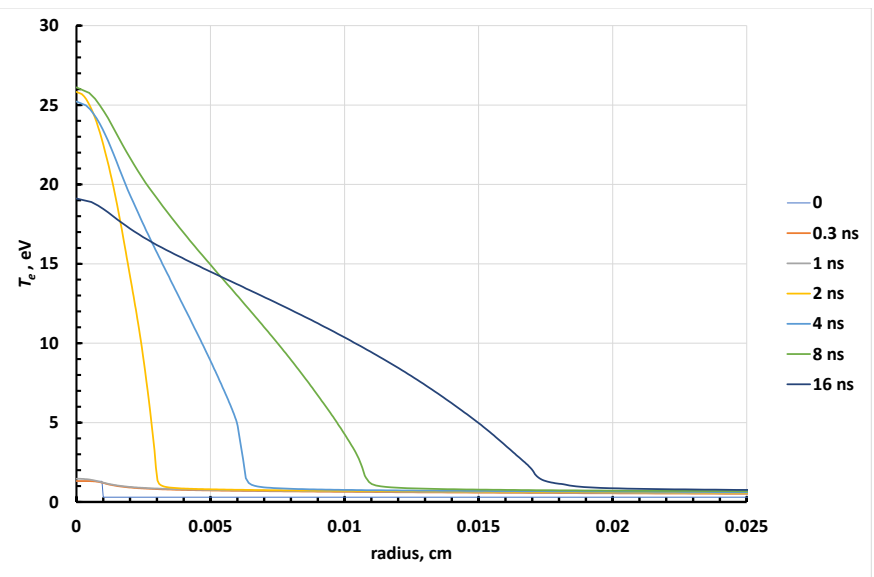

Fig. 35: Results of 1D simulation (Argon, diameter of heating region (FWHM) $=20 \mu \mathrm{m}, \Delta t / 2=2 \mathrm{~ns})$. Radial profiles of $T_{e}$ at different moments of time. 


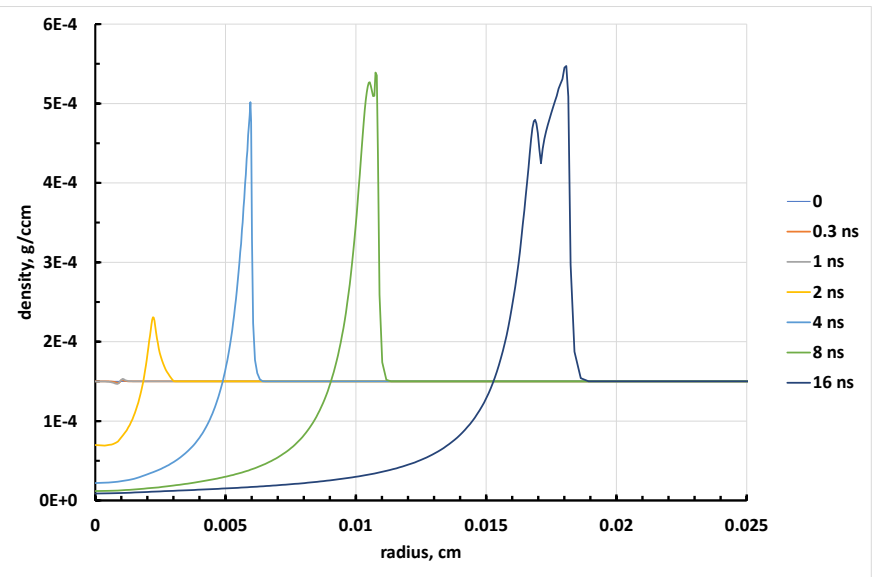

Fig. 36: Results of 1D simulation (Argon, diameter of heating region (FWHM) $=20 \mu \mathrm{m}, \Delta t / 2=2 \mathrm{~ns}$ ). Radial profiles of mass density at different moments of time.

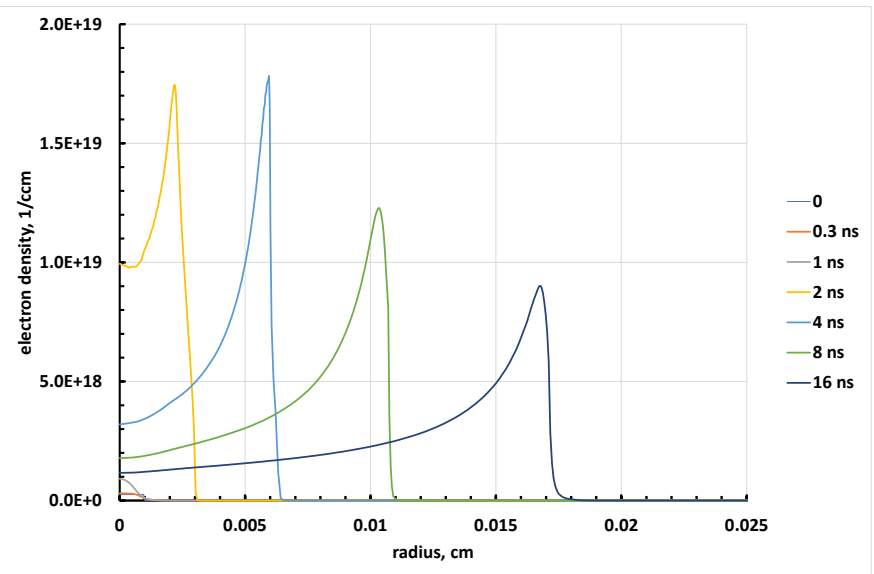

Fig. 37: Results of 1D simulation (Argon, diameter of heating region (FWHM) $=20 \mu \mathrm{m}, \Delta t / 2=2 \mathrm{~ns})$. Radial profiles of $n_{e}$ at different moments of time. 


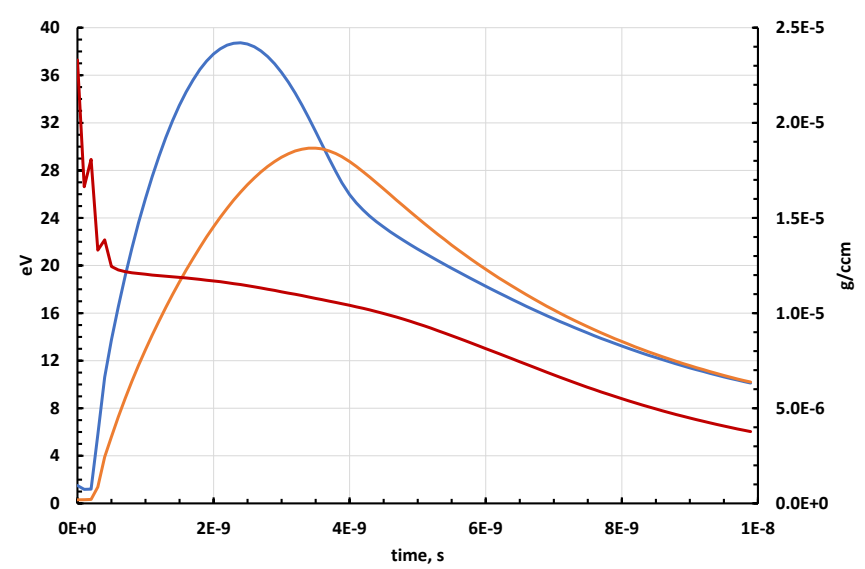

Fig. 38: Results of 1D simulation of plasma channel produced with Axicon lens ( $\ell / d=10$, Hydrogen, $6 \mathrm{~J}$ laser pulse, $2 \mathrm{~mm}$ diameter Axicon lens, $\tau=2 \mathrm{~ns}$ ). Temporal dependences of are axial temperatures and density.

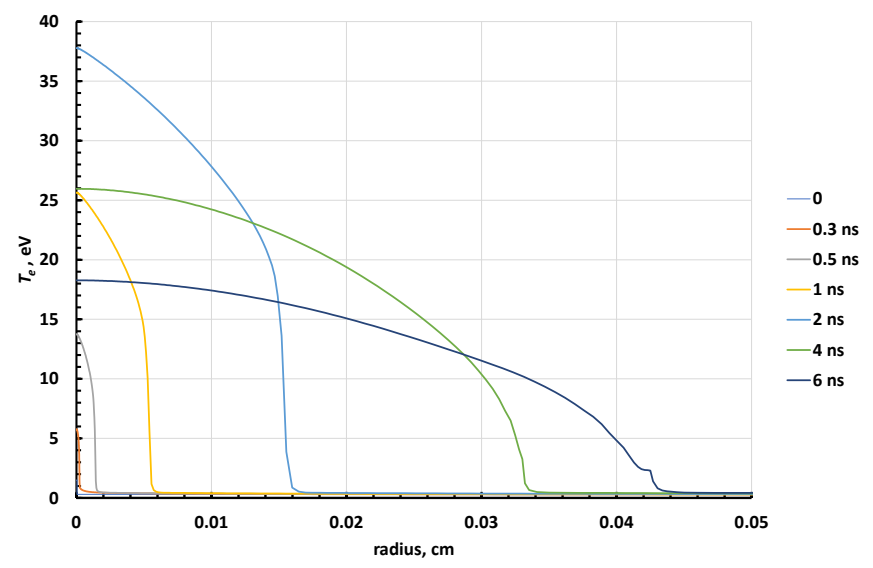

Fig. 39: Results of 1D simulation of plasma channel produced with Axicon lens ( $\ell / d=10$, Hydrogen, $6 \mathrm{~J}$ laser pulse, $2 \mathrm{~mm}$ diameter Axicon lens, $\tau=2 \mathrm{~ns}$ ). Radial profiles of $T_{e}$ at different moments of time. 


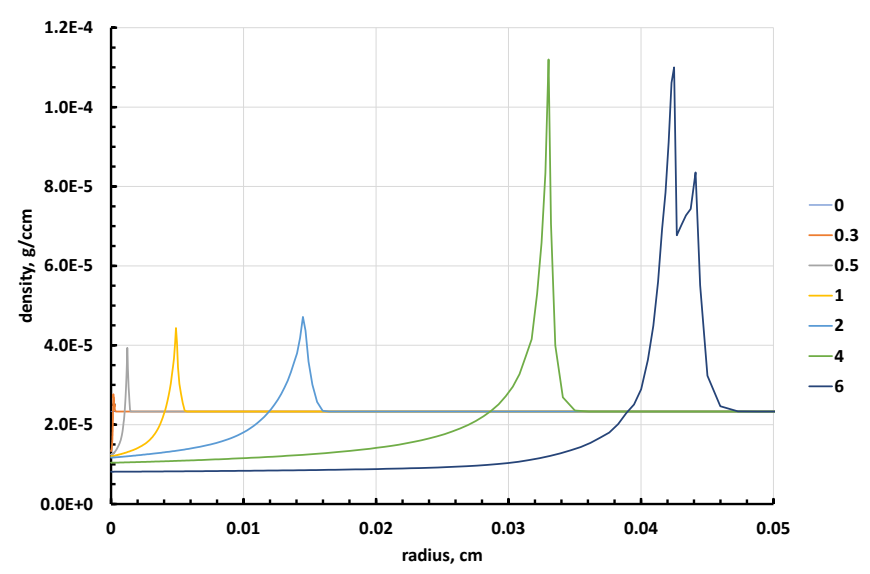

Fig. 40: Results of 1D simulation of plasma channel produced with Axicon lens $(\ell / d=10$, Hydrogen, $6 \mathrm{~J}$ laser pulse, $2 \mathrm{~mm}$ diameter Axicon lens, $\tau=2 \mathrm{~ns})$. Radial profiles of mass density at different moments of time.

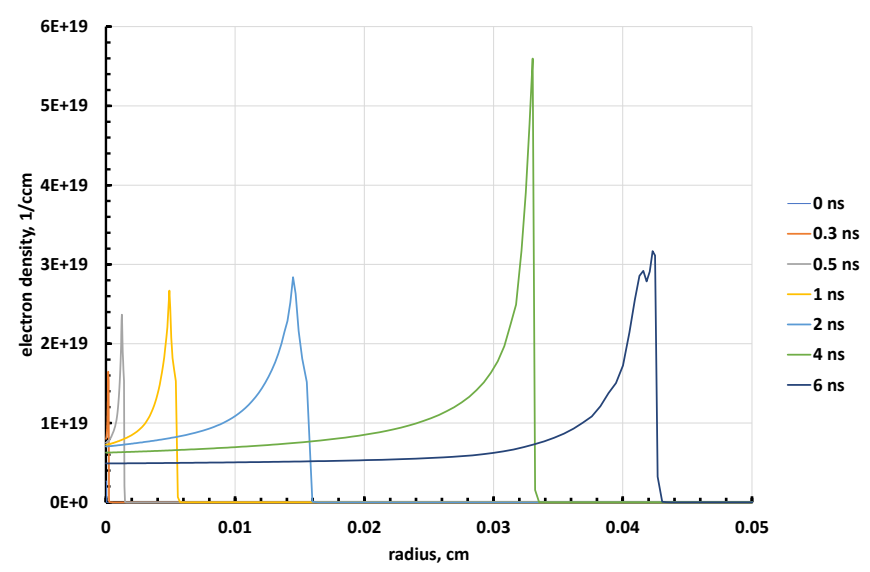

Fig. 41: Results of 1D simulation of plasma channel produced with Axicon lens $(\ell / d=10$, Hydrogen, $6 \mathrm{~J}$ laser pulse, $2 \mathrm{~mm}$ diameter Axicon lens, $\tau=2 \mathrm{~ns})$. Radial profiles of $n_{e}$ at different moments of time. 
set of the parameters for formation of channel structure of the plasma waveguide with acceptable quality.

In a naive way one can conclude that by waiting sufficiently long time we always may obtain sufficiently symmetric plasma channel. However, such a conclusion is the most probably erroneous. Indeed, we see that the hot plasma bubble at the moment of its formation is not azimuthally symmetric. This moment can be defined as a moment when the shock wave detaches from the hot bubble. The bubble becomes almost isobaric after this moment. Further evolution of the remaining bubble is governed mainly by thermal conduction and by vortex motions in the ambient gas. The vortices are exited just before this moment. Analogous to some extend problem is considered in Ref. [8], where the results of extensive simulations of similar problem are published. Their results indicate that the vortex motion leads to a strong mixing of the hot bubble with the ambient gas and to complete loss of symmetry. During the stage, when the shock wave is not detached from the hot bubble, the homogeneous ambient gas can help the symmetrization. In this case, the reaching of the most symmetric state of the hot bubble may take place right around the moment when the shock wave runs away. It means that our type of $2 \mathrm{D}$ simulations are capable to help in finding the optimal parameters mentioned above and that we have no need to perform very long 3D simulations.

Our 1D simulations with the code NPINCH take into account a wide range of additional parameters. The 1D simulations have obvious advantages in finding plasma channels parameters under the condition of approximate azimuthal symmetry.

\section{References}

[1] W. P. Leemans, A. J. Gonsalves, H.-S. Mao, K. Nakamura, C. Benedetti, C. B. Schroeder, Cs. Tóth, J. Daniels, D. E. Mittelberger, S. S. Bulanov, J.-L. Vay, C. G. R. Geddes, and E. Esarey, Phys. Rev. Lett. 113, 245002 (2014).

[2] M. Nevrkla, F. Nawaz, C. Lazzarini, G. Grittani, H. Zulic, T. Levato, T. Mocek, A. Lucianetti, D. Rostohar, "Waveguiding Plasma Channels at ElI-BL" , talk at "Seminar on Collaboration Project between LBNL (USA), ELI-BL (Czech Republic) and KIAM (Russia), (Dolny Brezany, Czech Republic, August 22, 2017).

[3] E. Ragozin, V. Levashov, K. Mednikov, A. Pirozhkov, P. Sasorov, "Interaction of a pulsed gas target with Nd-laser radiation and laser-produced plasma", in Advances in Laboratory-Based X-Ray Sources and Optics III, 
(Eds: A. M. Khounsary, and C. A. MacDonald), Proceedings of SPIE Vol. 4781, 17 (2002).

[4] N. A. Bobrova, P. V. Sasorov, C. Benedetti, S. S. Bulanov, C. G. R. Geddes, C. B. Schroeder, E. Esarey, and W. P. Leemans, "Laser-heater assisted plasma channel formation in capillary discharge waveguides", Physics of Plasmas 20, 020703 (2013).

[5] E. M. Lifshitz, and L. P. Pitaevskii, "Physical Kinetics", (Landau and Lifshitz, Course of Theoretical Physics, Vol. 10), (Pergamon Press plc, 2002). [Sec. IV.48]

[6] NRL Plasma Formulary. (1998) [Sec. "Atomic Physics and Radiation"]

[7] O. Svelto, "Principles of Lasers", 5th editions (Springer, NY, 2010).

[8] Y. Kurzweil, E. Livne, and B. Meerson, "Vorticity production and turbulent cooling of 'hot channels' in gases: Three dimensions versus two dimensions", Physics of Fluids 15, 752 (2003).

[9] G. Korn, and T. Korn, "Mathematical Handbook", (McGrow-Hill Book Co., NY), 1968. [see Table 6.5-5].

[10] L. Landau, and E. Lifshits, "Quantum mechanics", (Pergamon Press, Oxford, 1959) [see Eqs. (23.5) and (23.6) and explanations around them].

[11] L. Landau, and E. Lifshits,, "Electrodynamics of Continous Media", (Pergamon Press, Oxford, 1960).

[12] M. Abramovitz, and I. Stegun, "Handbook of Mathematical Functions and Formulas, Graphs and Mathematical Tables", 9th printing (N. V. Dover, NY), 1972. 


\section{A Two-dimensional distribution of EM field in the cylindrical focus region}

\section{A.1 2D s-polarised wave}

To calculate the energy deposition in gas target irradiated by a knife-like laser pulse one needs to find the EM field distribution in the focus region. We consider stationary electromagnetic field in vacuum. Assuming 2D geometry when all components of the EM wave depend on time and the coordinates $x$ and $y$. The electric and magnetic field in the focus region are given by:

$$
\begin{gathered}
\mathbf{E}(\mathbf{x}, t)=\left(E_{x}, E_{y}, E_{z}\right)=\left(0,0, E(x, y) e^{-i \omega t}\right), \\
\mathbf{B}(\mathbf{x}, t)=\left(B_{x}, B_{y}, B_{z}\right)=\left(B_{x}(x, y), B_{y}(x, y), 0\right) e^{-i \omega t},
\end{gathered}
$$

where $\omega=k c, k=2 \pi / \lambda$ is the wave number, $\lambda$ is the wavelength, and $E$ obeys the Hemholtz equation [11]:

$$
\nabla^{2} E+k^{2} E=0 .
$$

Here the operator $\nabla$ acts in the 2-dimensional space $(x, y)$, i.e. $\nabla=\left(\partial_{x}, \partial_{y}, 0\right)$. Physical $z$-component of electric field is equal to real part of the complex value E.

It is convenient to introduce elliptic cylindrical coordinates $\sigma$ and $\tau$ related to the Cartesian coordinates $(x, y)$-space [9], as

$$
\begin{aligned}
& \frac{y^{2}}{a^{2} \sigma^{2}}+\frac{x^{2}}{a^{2}\left(\sigma^{2}-1\right)}=1, \\
& \frac{y^{2}}{a^{2} \tau^{2}}+\frac{x^{2}}{a^{2}\left(\tau^{2}-1\right)}=1 .
\end{aligned}
$$

From these relationships it follows that

$$
y=a \sigma \tau, \quad x^{2}=a^{2}\left(\sigma^{2}-1\right)\left(1-\tau^{2}\right) .
$$

Here $\sigma \geq 1,-1 \leq \tau \leq 1$, and $a$ is a positive constant number. Its value will be determined below. Eq. (17) can be presented in the form [9].

$$
\sqrt{\sigma^{2}-1} \partial_{\sigma} \sqrt{\sigma^{2}-1} \partial_{\sigma} E+\sqrt{1-\tau^{2}} \partial_{\tau} \sqrt{1-\tau^{2}} \partial_{\tau} E=k^{2} a^{2}\left(\tau^{2}-\sigma^{2}\right) E .
$$

In Eq. (21) the coordinates $\sigma$ and $\tau$ can be separated. Solution of the equation Eq. (21) can be represented as:

$$
E(\sigma, \tau)=\Sigma(\sigma) T(\tau)
$$




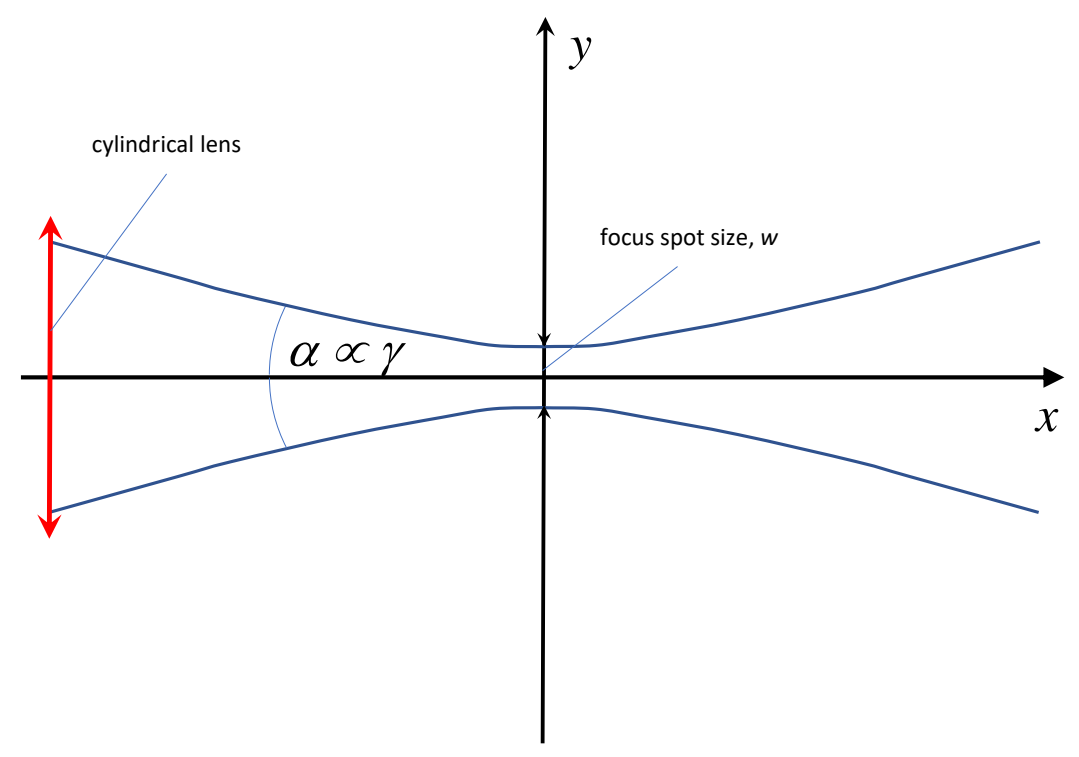

Fig. 42: Schematic of the problem. Thin blue lines show focused laser beam. Below we assume that the focus angle $\alpha$ is small.

Substituting it in Eq. (21) we obtain system of ordinary differential equations for $\Sigma$ and $T$ functions:

$$
\begin{aligned}
& \sqrt{\sigma^{2}-1} \frac{d}{d \sigma}\left(\sqrt{\sigma^{2}-1} \frac{d \Sigma}{d \sigma}\right)=\left(\Lambda-k^{2} a^{2} \sigma^{2}\right) \Sigma, \\
& \sqrt{1-\tau^{2}} \frac{d}{d \tau}\left(\sqrt{1-\tau^{2}} \frac{d T}{d \tau}\right)=-\left(\Lambda-k^{2} a^{2} \tau^{2}\right) T .
\end{aligned}
$$

Solutions of these equations can be expressed in terms of Mathieu functions [12]. For the sake of simplicity, in the next section we consider the case of small angle of the EM wave focusing.

\section{A.2 Small angle of focusing}

The schematic of the problem under consideration is illustrated by Fig. 42. We assume the angle $\alpha$ of of the laser beam focusing is small compared to unity, whereas the transverse distribution of intensity across the beam is gaussian.

The function $T(\tau)$ may have a gaussian form in the region of localization $|\tau| \ll 1$, provided exponentially small tails are excluded. In this case Eq. (24) can be written as:

$$
\frac{d^{2} T}{d \tau^{2}}+\left(\Lambda-k^{2} a^{2} \tau^{2}\right) T=0 .
$$


This yields for the ground mode with the lowest $\Lambda$, when $T$ has no zeros and tends to 0 large $\tau$ :

$$
T \propto e^{-k a \tau^{2} / 2},
$$

with $\Lambda=k a$, which assumes that $k a \gg 1$. General solutions of Eq. (26), tending to 0 at large $\tau$, can be expressed in terms of Hermite polynomials [12]. If $k a \gg 1$, then the equation (23) for the function $\Sigma$, takes the form:

$$
\sqrt{\sigma^{2}-1} \frac{d}{d \sigma}\left(\sqrt{\sigma^{2}-1} \frac{d \Sigma}{d \sigma}\right)=\left(k a-k^{2} a^{2} \sigma^{2}\right) \Sigma .
$$

can be solved within the framework of the WKB approximation, i.e. its solution can be written in the form:

$$
\Sigma=b e^{i S},
$$

where $S$ and $\left|\frac{d S}{d \sigma}\right|$ are the functions of $\sigma$, much larger than 1 , whereas $b$ is smoothly varying pre-exponent. It is easy to obtain obtain that

$$
\left(\frac{d S}{d \sigma}\right)^{2}=k^{2} a^{2} \frac{\sigma^{2}}{\sigma^{2}-1},
$$

which yields

$$
S=k a \sqrt{\sigma^{2}-1}
$$

The pre-exponent $b$ obeys the equation:

$$
\left(2 S^{\prime} b^{\prime}+S^{\prime \prime} b\right)\left(\sigma^{2}-1\right)+S^{\prime} b \sigma=-i k a b .
$$

where the prime denotes the differentiating with respect to the variable $\sigma$. Presenting the solution of this linear ordinary differential equation of the first order in the form:

$$
b=|b| e^{i \phi},
$$

we obtain for the amplitude $|b|$ and phase $\phi$ :

$$
|b| \propto \frac{1}{\sqrt{\sigma}}, \quad \phi=\arctan \frac{1}{\sqrt{\sigma^{2}-1}}
$$

Substituting obtained expressions in Eq. (22), and using the relationships (20) at small $|\tau|$, we obtain for the square of the electric field:

$$
|E|^{2} \propto \frac{1}{\sqrt{x^{2}+a^{2}}} \exp \left(-k a \frac{y^{2}}{x^{2}+a^{2}}\right) .
$$


We can define the angle $\alpha$ as an angle at which the intensity of laser beam becomes $e$ times lower at $x \rightarrow-\infty$ than intensity at the central plane $y=0$ of the beam. This gives for the focus angle

$$
\alpha=\frac{1}{\sqrt{k a}} \quad \text { at } \quad k a \gg 1 .
$$

Substituting this relationship into Eq. (34), we obtain that the square of absolute value the electric field $E$ depends on the coordinates $x$ and $y$ as:

$$
|E|^{2} \propto \frac{1}{\sqrt{\alpha^{4} k^{2} x^{2}+1}} \exp \left(-\frac{\alpha^{2} k^{2} y^{2}}{\alpha^{4} k^{2} x^{2}+1}\right) .
$$

Here we have analyzed the case of the polarization of EM wave. It is easy to find that if the focal angle is small, $\alpha \ll 1$, the $|E|^{2}$ distribution does not depend in the leading order on the polarization of the EM-wave.

There is the following relationship between averaged over period of the electro-magnetic field Poynting vector and $|E|$ in our paraxial case:

$$
F=c \frac{\left\langle(\mathbf{E} \times \mathbf{B})_{z}\right\rangle}{4 \pi}=c \frac{|E|^{2}}{8 \pi} .
$$

Introducing the intensity $J$ of the knife-like laser beam in terms of its power

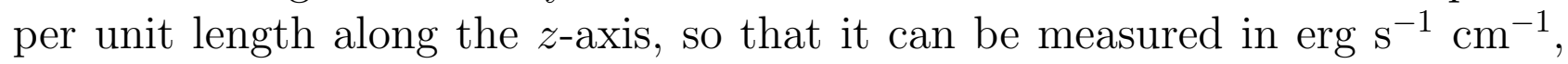
the Eq. (35) can be rewritten as:

$$
F=\frac{|E|^{2}}{8 \pi} c=J \frac{\alpha k}{\sqrt{\pi} \sqrt{\alpha^{4} k^{2} x^{2}+1}} \exp \left(-\frac{\alpha^{2} k^{2} y^{2}}{\alpha^{4} k^{2} x^{2}+1}\right) .
$$

This equation is used in the main body of our paper. 